\title{
Anti-Inflammatory Potential of Green Synthesized Silver Nanoparticles of the Soft Coral Nephthea Sp. Supported by Metabolomics Analysis and Docking Studies
}

This article was published in the following Dove Press journal:

International Journal of Nanomedicine

\author{
Omnia Hesham Abdelhafez' \\ Taha Farouk Shehata Ali (iD) ${ }^{2}$ \\ John Refaat Fahim ${ }^{3}$ \\ Samar Yehia Desoukey ${ }^{3}$ \\ Safwat Ahmed ${ }^{4}$ \\ Fathy A Behery ${ }^{5,6}$ \\ Mohamed Salah Kamel ${ }^{3}$ \\ Tobias AM Gulder ${ }^{7}$ \\ Usama Ramadan Abdelmohsen ${ }^{1,3}$ \\ 'Department of Pharmacognosy, Faculty of \\ Pharmacy, Deraya University, New Minia \\ 6 III I, Egypt; ${ }^{2}$ Department of Medicinal \\ Chemistry, Faculty of Pharmacy, Minia \\ University, Minia 61519, Egypt; ${ }^{3}$ Department \\ of Pharmacognosy, Faculty of Pharmacy, \\ Minia University, Minia 61519, Egypt; \\ ${ }^{4}$ Department of Pharmacognosy, Faculty of \\ Pharmacy, Suez Canal University, Ismailia \\ 4I522, Egypt; ${ }^{5}$ Department of \\ Pharmacognosy, Faculty of Pharmacy, \\ Mansoura University, Mansoura 355I6, \\ Egypt; ${ }^{6}$ Department of Pharmaceutical \\ Sciences, College of Pharmacy, Riyadh Elm \\ University, Riyadh II68I, Saudi Arabia; \\ ${ }^{7}$ Chair of Technical Biochemistry, \\ Department of Chemistry and Food \\ Chemistry, Technical University of Dresden, \\ Dresden 01069, Germany
}

Correspondence: Usama Ramadan Abdelmohsen

Department of Pharmacognosy,Faculty of Pharmacy,Minia University, Minia 61519,

Egypt

Email Usama.ramadan@mu.edu.eg

Tobias AM Gulder

Chair of Technical Biochemistry,

Department of Chemistry and Food

Chemistry, Technical University of Dresden,

Bergstraße 66, Dresden 01069, Germany

Email tobias.gulder@chemie.tu-dresden.de
Background: Soft corals have been endorsed as a plentiful source of bioactive compounds with promising anti-inflammatory activities; therefore, exploring their potential as source of anti-inflammatory metabolites has stimulated a growing research interest.

Purpose: To investigate the anti-inflammatory potential of the soft coral, Nephthea sp., in its bulk and silver nanostructure. Metabolomics analysis of Nephthea sp., followed by molecular docking studies, was also conducted in order to explore and predict the secondary metabolites that might provide its inhibitory actions on inflammation.

Materials and Methods: The petroleum ether and ethyl acetate fractions were used to synthesize silver nanoparticles. The prepared silver nanoparticles were characterized through UV-vis spectrophotometric, transmission electron microscopy (TEM) and Fourier-transform infrared spectroscopy (FTIR) analyses. Testing for the anti-inflammatory activity was performed against COX-1 and COX-2. Furthermore, liquid chromatography-mass spectrometry (LC-MS) based metabolomics analysis and molecular docking were also applied.

Results: A variety of secondary metabolites were identified, among them, sesquiterpenes were found to prevail. The petroleum ether and acetone fractions of Nephthea sp. showed the highest COX-2 inhibitory activities, possibly attributable to their substantial contents of terpenoids. Additionally, the green synthesized silver nanoparticles of both the petroleum ether and ethyl acetate fractions of Nephthea sp. demonstrated higher anti-COX-2 properties.

Conclusion: The obtained results showed the effectiveness of non-targeted metabolomics technique in metabolic profiling of Nephthea sp., helping the search for new bioactive metabolites in future chemical studies on this soft coral. The interesting anti-inflammatory potential of the tested extracts and their nanoparticles could also be relevant to the development of new, effective anti-inflammatory agents.

Keywords: anti-inflammatory, metabolomics, molecular docking, nanoparticles, Nephthea, soft coral

\section{Introduction}

Inflammation is a pathological condition that represents a part of our immune system response to harmful stimuli, eg, irritants, injured cells, and pathogens. ${ }^{1}$ Recently, a variety of appalling chronic diseases have been proven to be associated with inflammation, such as rheumatoid arthritis, ${ }^{2}$ atherosclerosis, ${ }^{3}$ diabetes, ${ }^{4}$ Alzheimer's, ${ }^{5}$ 
inflammatory bowel disease, ${ }^{6}$ and cancer. ${ }^{7}$ Inflammatory processes usually involve several cell types encompassing neutrophils, basophils, eosinophils, and mononuclear cells (eg, monocytes and macrophages). ${ }^{8-10}$ Some pro- and anti-inflammatory mediators are also commonly produced during inflammation, including cytokines, chemokines, tumor necrosis factor- $\alpha$, and inducible enzymes, such as cyclooxygenase- 2 (COX-2) and inducible NO synthase (iNOS), which play some key regulatory roles. ${ }^{1,11}$ Therefore, different mechanisms and mediators implicated in painful and inflammatory states have been the focus of numerous recent studies. ${ }^{12}$ Additionally, in spite of the available arsenal of anti-inflammatory agents, typically represented by glucocorticoids, nonsteroidal anti-inflammatory drugs, and immunosuppressants, the therapy seems to be not effective enough and is also constrained by many undesired side effects, ${ }^{13-15}$ deepening the need for discovering other new anti-inflammatory drug candidates.

Natural products represent a long-standing and fruitful source of ubiquitous drug leads, offering both noteworthy structural diversity and varied biological potential. ${ }^{16}$ Oceans, which cover about $70 \%$ of our earth' surface, have attracted a special interest owing to their exceptionally important biodiversity. ${ }^{17}$ To date, marine organisms have provided wide-ranging natural compounds with promising antimicrobial, antiviral, antimalarial, antitumor, antioxidant, and antiinflammatory properties. ${ }^{18,19}$ Among them, soft corals, a group of marine invertebrates found within the coral reefs of most oceans, are a biochemical storeroom of important secondary metabolites, eg, sesquiterpenes, ${ }^{20}$ diterpenes, ${ }^{21}$ and sterols, ${ }^{22}$ which are endowed with antifouling, antiviral, antitumor, and anti-inflammatory activities. ${ }^{23,24}$ In this regard, some potent anti-inflammatory molecules have been described from soft corals, exemplified by isoparalemnone, which was obtained from the Formosan soft coral Paralemnalia thyrsoides. This sesquiterpene was reported to significantly inhibit the expression of inflammatory iNOS protein by $70 \%$ at $10 \mu \mathrm{mol} / \mathrm{L}$ in activated RAW 264.7 cells. $^{25}$ Likewise, the sesquiterpene erectathiol isolated from Nephthea erecta KUKENTHAL displayed substantial in vitro anti-inflammatory actions, as indicated by the remarkable reduction in the levels of both iNOS and COX2 proteins by $58.0 \pm 6.5$ and $108.7 \pm 4.5 \%$, respectively. ${ }^{26}$

On the other hand, the application of modern interdisciplinary scientific approaches has increasingly contributed to recent drug discovery, including among others, metabolomics and nanoscience. Metabolomics is a valuable analytical tool used in the comprehensive, high throughput determination of metabolites in a given metabolome. ${ }^{27}$ It has recently gained growing importance in chemical profiling of various natural sources, such as medicinal plants, ${ }^{28}$ marine organisms, ${ }^{29}$ and bacteria. ${ }^{30}$ This privileged technique allows the rapid identification (dereplication) and quantification of secondary metabolites in crude unfractionated extracts; avoiding laborious chromatographic work and reducing the time wasted in the re-isolation of known compounds. ${ }^{31}$ In the same context, nanoscience has been established as a new interdisciplinary field that is concerned with the understanding and controlling of matter within the size range of $1-100 \mathrm{~nm} .{ }^{11}$ Nanomaterials typically enjoy unique physicochemical properties, eg, very small size, large surface area to mass ratio, and high reactivity, giving them superior bioactivities to bulk materials of identical composition. Thus, they have found wide applications in medical sciences mostly to innovate new therapeutic and diagnostic remedies. ${ }^{32}$

Recently, there is a great interest in utilizing noble metals for nanoparticle production in different industrial and pharmaceutical aspects. ${ }^{33}$ Chemical methods used in preparation of nanoparticles have shown numerous limitations, such as the formation, monodispersity of the particles, and thermodynamic stability. ${ }^{34}$ On the other hand, green synthesis is a preferred approach due to lower toxicity, inceased feasibility and safety. ${ }^{35}$ Silver nanoparticles have attracted much interest owing to their applications in industrial and therapeutic approaches. $^{34,36,37}$ Silver nanoparticles exhibited potent antibacterial potential against: gram positive, gram-negative, methicillin-resistant strains and also anti-biofilm properties.${ }^{38,39}$ Das et al have demonstrated that green synthesis of silver nanoparticles from Ocimum gratissimum $L$. leaf extract gave material that exhibited anti-bacterial potential against Escherichia coli. It was also found as an effective inhibitor of bio-film formation in both types of strains through destroying the bacterial cell membrane followed by ROS production. ${ }^{38}$ Additionally, silver nanoparticles prepared by Rosa canina had highly effective anti-oxidant, antibacterial, antifungal, and DNA cleavage activities. ${ }^{40}$ Silver nanoparticles also exhibited potent cytotoxic potential against a panel of cell lines ${ }^{41,42}$ together with interesting anti-inflammatory potential, ${ }^{43}$ larvicidal activity ${ }^{44}$ and wound healing properties. ${ }^{45}$

Green synthesis of nanoparticles using marine organisms is underexplored. The marine sponge Acanthella elongate has been used for the synthesis of silver nanoparticles, which was clearly confirmed by UV-visible spectrum, TEM analysis, FT-IR and X-ray diffraction. ${ }^{46}$ The red algae Gelidium corneum extract acted as a reducing agent in the synthesis of silver nano samples. The formed 
nanoparticles showed potent anti-biofilm efficacy. ${ }^{47}$ Additionally, the silver nanoparticles formed from the red algae Spyridia filamentosa exhibited potent antibacterial activity against Staphylococcus sp. and Klebsiella sp. and cytotoxic potential against MCF-7 cell lines. ${ }^{48}$

Few studies have been conducted to evaluate the antiinflammatory potential of green synthesized silver nanoparticles with their possible mechanism of action. ${ }^{49}$ Although, the green synthesis of nanoparticles has attracted great attention in the last few decades, till now, no studies have been conducted to evaluate the anti-inflammatory activity of soft corals. Our study aims to investigate the in-vitro anti-inflammatory potential against COX-1 and COX-2 of the crude extract and its derived fractions, as well as, the green synthesized silver nanoparticles from Nephthea sp. petroleum ether and ethyl acetate fractions. Furthermore, we utilized an untargeted metabolomics approach to unveil the chemical profile of the total extract and different fractions of the soft coral; Nephthea sp. using liquid chromatography coupled with high-resolution electrospray ionisation mass spectrometry (LC-HR-ESIMS), followed by docking analysis of all the dereplicated compounds to explore the chemical constituents that might contribute to the anti-inflammatory potential.

\section{Materials and Methods Soft Coral Material}

The soft coral Nephthea sp. was collected by Prof. Safwat Ahmed, Professor of Pharmacognosy, Faculty of Pharmacy, Suez Canal University, Egypt, by scuba diving from the Egyptian coasts of the Red Sea at Sharm el-Sheikh at a depth of $10 \mathrm{~m}$. It was then stored at $-20^{\circ} \mathrm{C}$ until investigation. The animal biomass was identified by Dr. Tarek Temraz, Marine science Department, Faculty of Science, Suez Canal University, Ismailia, Egypt. A voucher specimen was deposited in the herbarium section of Pharmacognosy Department, Faculty of Pharmacy, Suez Canal University, Ismailia, Egypt under registration number SAA-26.

\section{Chemicals and Reagents}

Organic solvents used in this study, including n-butanol, ethyl acetate, acetone, dichloromethane, and petroleum ether (b.p. $60-80^{\circ} \mathrm{C}$ ) were of analytical grade and distilled prior to use. Dimethylsulfoxide (DMSO) was used in the preparation of silver nanoparticles. All these solvents were purchased from El-Nasr Company for Pharmaceuticals and Chemicals, Egypt. Solvents of HPLC grade such as acetonitrile and methanol were obtained from SDFCL sd fine-Chem
Limited, India. Both silver nitrate $\left(\mathrm{AgNO}_{3}\right.$; purity $\left.\geq 99.5 \%\right)$ and the ion exchange resin were purchased from SigmaAldrich, Germany. Celecoxib and indomethacin were purchased from Sigma-Aldrich, Germany and used as standard anti-inflammatory drugs.

\section{Extraction and Fractionation}

The collected soft coral was freeze-dried, then extracted with methylene chloride - methanol (1:1) until exhaustion. ${ }^{50}$ The concentrated organic extract $(24.0 \mathrm{~g})$ was suspended in distilled water and extracted successively with different organic solvents, including petroleum ether, ethyl acetate and n-butanol. The remaining mother liquor was deprived of its content of sugars and salts by an ion exchange resin using acetone. The organic phase in each step was separately concentrated under vacuum, yielding the petroleum ether fraction I (10.0 $\mathrm{g})$, the ethyl acetate fraction II ( $3.0 \mathrm{~g})$, the n-butanol fraction III $(3.0 \mathrm{~g})$, and the acetone fraction IV $(200.0 \mathrm{mg})$. The total extract and its derived fractions were kept at $4^{\circ} \mathrm{C}$ for metabolomics and biological investigation. ${ }^{51}$

\section{Synthesis of Silver Nanoparticles (SNPs)}

The green silver nanoparticles were prepared by separately dissolving $0.005 \mathrm{~g}$ of each of the petroleum ether and ethyl acetate fractions in $1 \mathrm{~mL}$ DMSO. Then, 0.2 $\mathrm{mL}$ of each sample solution were added to $10 \mathrm{~mL}$ of 1 $\mathrm{mM} \mathrm{AgNO} 3$ and the reaction mixture was kept for $48 \mathrm{~h}$ at room temperature. ${ }^{52}$ Unfortunately, both the n-butanol and acetone fractions failed to be converted into nanoparticles, as clearly confirmed by monitoring the color change of the reaction mixtures during their preparation.

\section{Characterization of the Synthesized SNPs by Transmission Electron Microscopy (TEM)}

For TEM analysis, a drop of the silver nanoparticles' solution was added on a copper grid and coated with a carbon support film. After complete drying, the shape and size of SNPs were investigated utilizing a Transmission Electron Microscope (Jeol model JEM-1010, USA) at The Regional Center for Mycology and Biotechnology, AlAzhar University, Cairo, Egypt.

\section{Characterization of the Synthesized SNPs by UV-Visible Analysis}

UV-visible analysis was performed to observe the development of SNPs. The analysis was achieved by using a 
double beam V-630 spectrophotometer, Jasco, Japan at the Faculty of Pharmacy, Ain-Shams University, Cairo, Egypt at the wavelength range of $200-600 \mathrm{~nm}$.

\section{Characterization of the Synthesized SNPs by Fourier-Transform Infrared Spectroscopy (FTIR)}

A FT-IR-8400S, IR Prestige-21, IR Affinity-1, Shimadzu, Japan, at the Faculty of Pharmacy, Cairo University, Cairo, Egypt, was employed for characterization of the possible functional groups attached to the surface of SNPs.

\section{Determination of Particle Size Distribution (Z-Average Mean) by Zeta Sizer Using DLS Technique}

The nanoparticles particle size distribution was studied using a Zeta-sizer Nano ZS (Malvern instruments) in a disposable cell at $25^{\circ} \mathrm{C}$, and the results were analyzed using Zeta-sizer 7.01 software, United Kingdom.

\section{Metabolomics Analyses}

Metabolic profiling of the methylene chloride-methanolic extract of the soft coral; Nephthea sp. and its derived fractions was carried out as described by Abdelmohsen et al. ${ }^{31,51}$ using an Acquity Ultra Performance Liquid Chromatography system connected to a Synapt G2 HDMS quadrupole timeof-flight hybrid mass spectrometer (Waters, Milford, USA). Chromatographic separation was carried out using a BEH C18 column $(2.1 \times 100 \mathrm{~mm}, 1.7 \mu \mathrm{m}$ particle size; Waters, Milford, USA) accompanied with a guard column $(2.1 \times$ $5 \mathrm{~mm}, 1.7 \mu \mathrm{m}$ particle size). The mobile phase used during the separation consisted of purified water (A) and acetonitrile
(B) with $0.1 \%$ formic acid added to each solvent. A gradient elution started at a flow rate of $300 \mu \mathrm{L} / \mathrm{min}$ with $10 \% \mathrm{~B}$ linearly increased to $100 \% \mathrm{~B}$ within $30 \mathrm{~min}$ and remained isocratic for the next $5 \mathrm{~min}$ before linearly decreasing back to $10 \% \mathrm{~B}$ for the following $1 \mathrm{~min}$. The volume injected was 2 $\mu \mathrm{L}$ and the column temperature was adjusted to $40^{\circ} \mathrm{C}$. The obtained raw data were separated into positive and negative ionization mode using MSConvert software. Accordingly, the files were imported to the data mining software MZmine 2.10 for peak picking followed by deconvolution, deisotoping, alignment, and formula prediction. Dictionary of Natural Products (DNP) and Marinlit databases were used for the identification of compounds. ${ }^{53,54}$

\section{Anti-Inflammatory Activity}

The anti-inflammatory activity $\left(\mathrm{IC}_{50}\right.$ values in $\left.\mu \mathrm{M}\right)$ of the total extract and different fractions of Nephthea sp. against ovine COX-1 and human recombinant COX-2 enzymes was determined by measuring prostaglandin $\mathrm{F} 2 \alpha$ (PGF2 $\alpha$ ) using a COX Inhibitor Screening Kit (Catalog No 560,131) from Cayman Chemical, Ann Arbor, Michigan, USA following the procedure suggested by the manufacturer. ${ }^{55}$

\section{Molecular Docking Study}

The X-ray structures of COX-1 (using the pdb entry 5WBE cocrystallized with mofezolac) ${ }^{56}$ and COX-2 (using the pdb entry 5 KIR cocrystallized with rofecoxib) ${ }^{57}$ were retrieved from protein data bank and used in the present docking study. The structure preparation module in MOE 2019.01 (Chemical Computing Group, Montreal, QC, Canada) was applied in the preparation of the protein structures. ${ }^{58}$ All water molecules were removed from the structure. For both COX isoforms, the co-crystallized ligand was defined as the
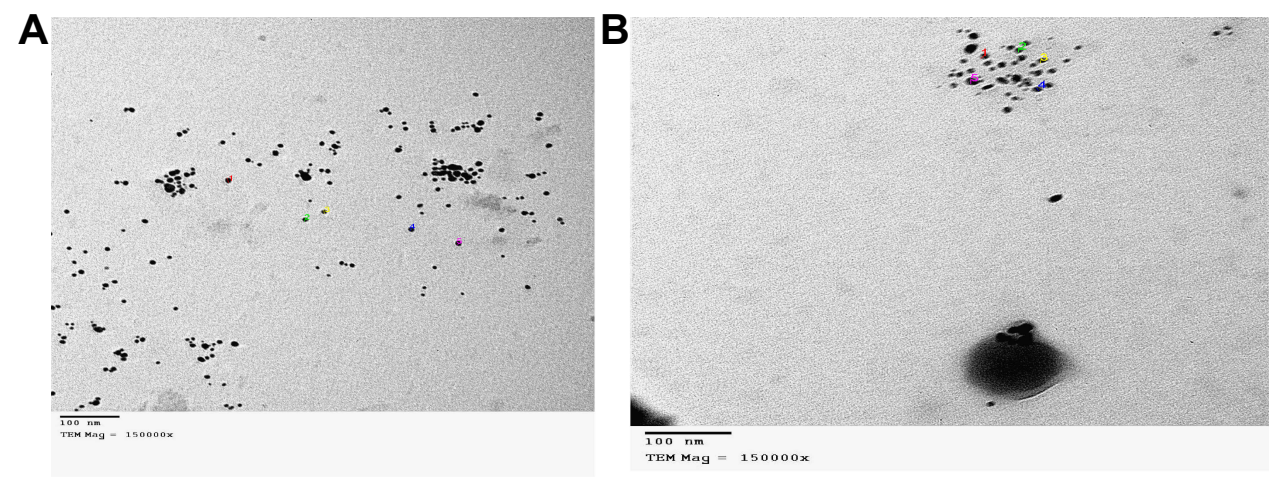

Figure I TEM photos of the formed silver nanoparticles of the petroleum ether $(\mathbf{A})$ and ethyl acetate (B) fractions of Nephthea sp. 

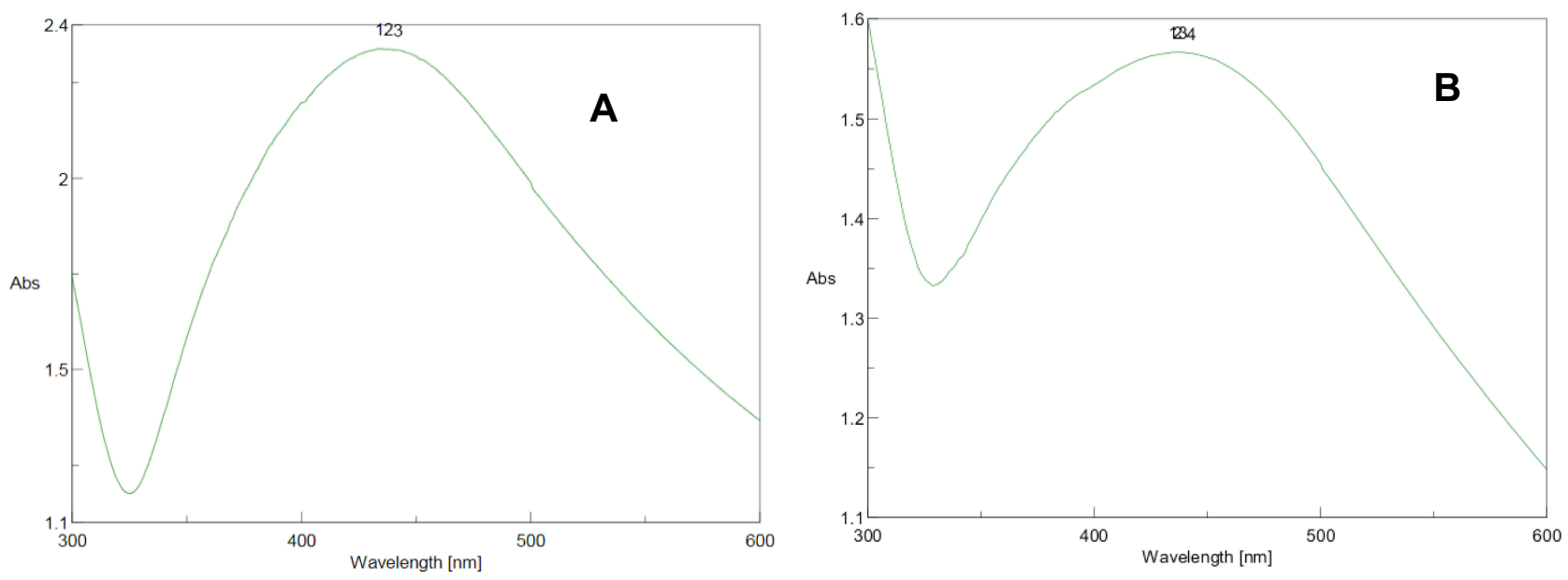

Figure 2 UV-Vis spectra after synthesis of nanoparticles using the petroleum ether (A) and ethyl acetate (B) fractions of Nephthea sp.
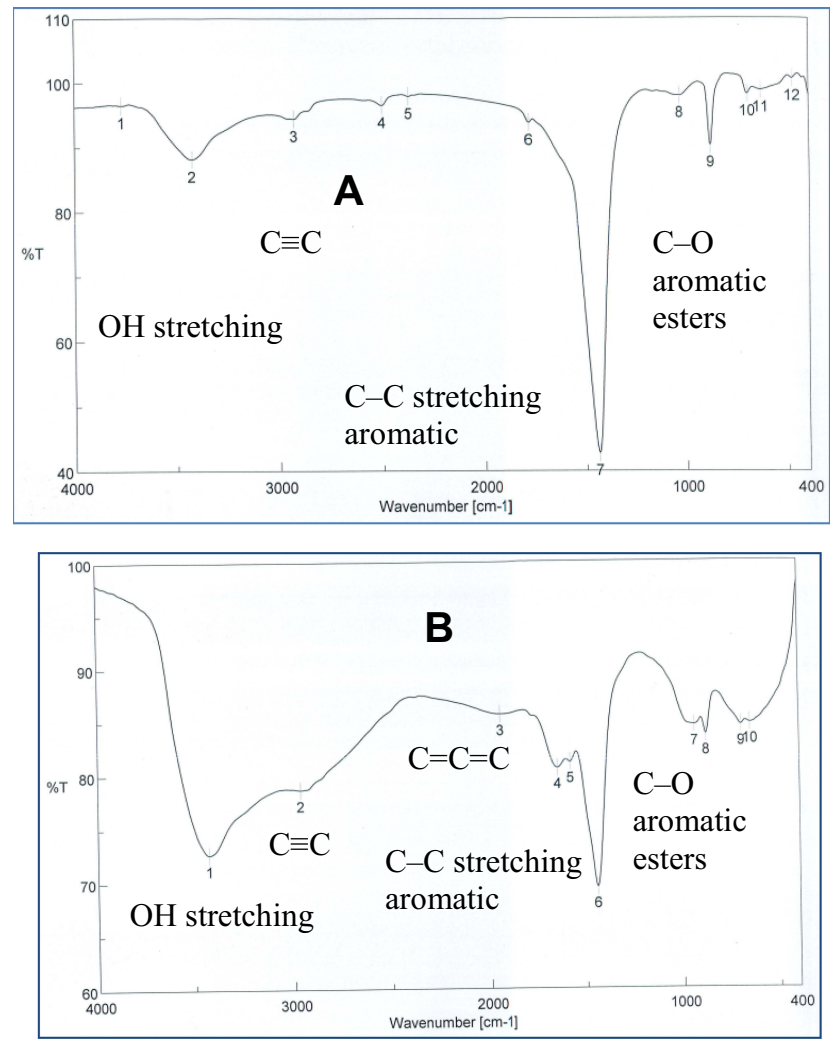

Figure 3 FTIR spectra after synthesis of nanoparticles using the petroleum ether (A) and ethyl acetate (B) fractions of Nephthea sp.

center of the binding site. All the identified compounds (110) were docked using the rigid-receptor method. ${ }^{59}$ Three hundred docking poses were calculated for each compound. All other options were left at their default standards. The cocrystallized ligand was also docked with other compounds for validation of the docking method. The resulting docking poses were visualized using MOE 2019.01.

\section{Results and Discussion}

\section{Synthesis and Characterization of SNPs}

Treatment of the petroleum ether and ethyl acetate fractions of Nephthea sp. with $1 \mathrm{mM} \mathrm{AgNO}_{3}$ has markedly changed their colors to brown, which is an early sign for SNPs formation as represented in (Figure S1). Such a color transition is due to the excitation of surface plasmon, its vibrations and the reduction of the $\mathrm{Ag}^{+}$to $\mathrm{Ag}^{0}$ by some of the secondary metabolites present in the petroleum ether and ethyl acetate fractions. ${ }^{52,60,61}$

\section{TEM Characterization of the Synthesized SNPs}

TEM analysis was used to investigate the size and shape of the petroleum ether and ethyl acetate fractions of Nephthea sp. nano-samples. The green synthesized silver nanoparticles were spherical in shape with mean size ranges of 8.59-11.19 and 5.28-8.34 $\mathrm{nm}$ for the petroleum ether and ethyl acetate fractions, respectively (Figure 1A and $\mathrm{B}$ ).

\section{UV-Vis Characterization of the Synthesized SNPs}

The formation of silver nanoparticles was depicted by UVVis spectrometry as one of the most broadly utilized approaches for structural characterization of silver nanoparticles. ${ }^{52}$ Therefore, the formation and optimization of SNPs were observed by measuring the absorbance in the range of 200-600 $\mathrm{nm}$. Consequently, an absorbance band was observed at $417 \mathrm{~nm}$, which is similar to that reported in the literature (Figure 2). ${ }^{62,63}$ 


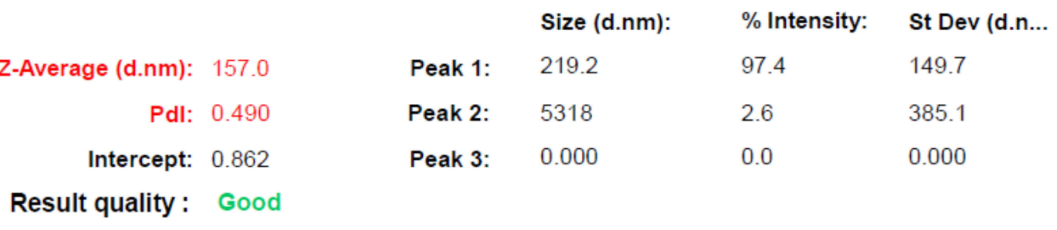

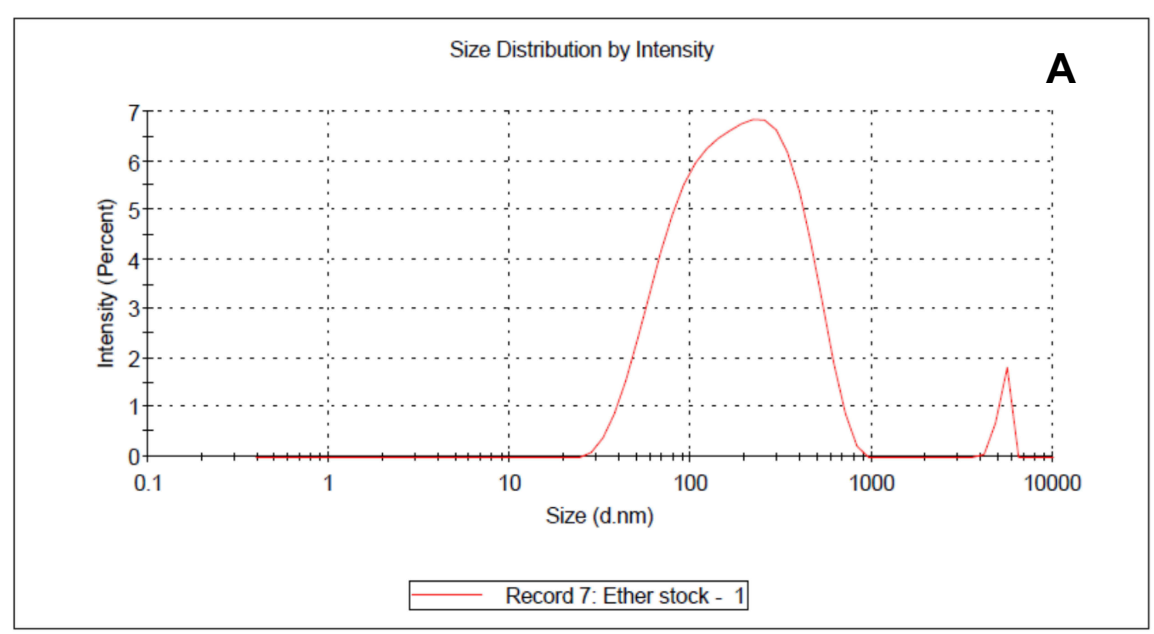

\begin{tabular}{|c|c|c|c|c|}
\hline & & Size (d.nm): & $\%$ Intensity: & St Dev (d.n... \\
\hline Z-Average (d.nm): 178.3 & Peak 1: & 258.0 & 93.2 & 158.1 \\
\hline Pdl: 0.451 & Peak 2: & 4905 & 3.9 & 672.4 \\
\hline Intercept: 0.917 & Peak 3: & 23.51 & 2.9 & 6.527 \\
\hline
\end{tabular}

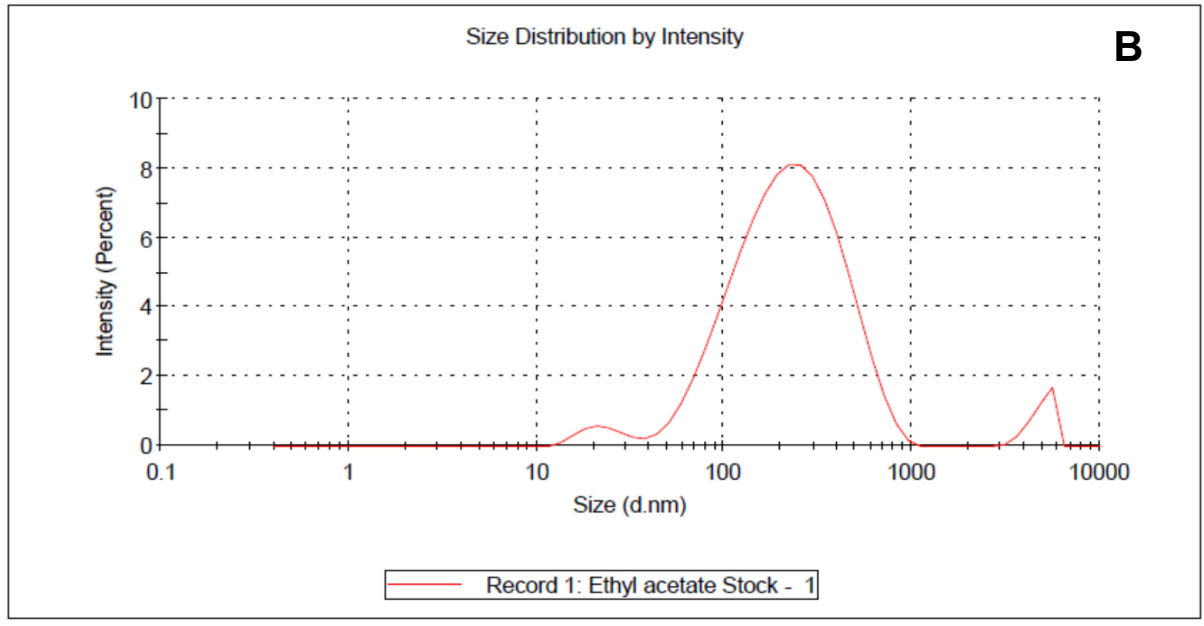

Figure 4 Dynamic light scattering analysis of synthesized SNPs (A) Pet. ether nano extract, (B) ethyl acetate nano extract.

\section{FTIR Characterization of the Synthesized SNPs}

FTIR measurements were carried out to explore the biomolecules' functional groups accountable for the reduction of silver ions and capping of SNPs. ${ }^{64}$ The obtained FTIR spectra demonstrated various absorption bands at $3572.17,3421.72,3414,3390.86,2083.12$, $1913.39, \quad 1643.35, \quad 1635.64, \quad 1392.61, \quad 1284.59$, 1246.02, 1222.87, 1076.28, 505.35, 470.63, 450.06, 435.91, and $428.20 \mathrm{~cm}^{-1}$ (Figure $3 \mathrm{~A}$ and $\mathrm{B}$ ). Among them, the absorption bands in the range of $3200-3500 \mathrm{~cm}^{-1}$ were assigned as $-\mathrm{OH}$ stretching for 
<smiles>C[C@H]1CCC[C@]2(C)C=CC(=O)C=C12</smiles>

1<smiles>[2H][C@@H]1C[C@@H](O)[C@H]2O[C@]23CCC(=O)[C@H](C(C)=O)[C@]13C</smiles><smiles>C=C1CCC=C2C=CC(=C2C)C1</smiles>

2<smiles></smiles><smiles>CC1=C2[C@@H](CC1=O)[C@@H](C)CC[C@H]1[C@H](C)[C@@H]2C1(C)C</smiles>

3<smiles>C=CC(C)(O)[C@]1(C)CC[C@](C)(/C=C2/C=C(C)C(=O)O2)OO1</smiles>

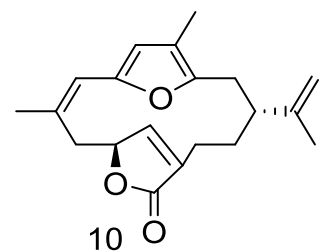<smiles>C[C@H]1CCC=C2CC[C@@H]3OC(=O)[C@H](C)[C@H]3[C@]21C</smiles><smiles>CC(=O)CC/C=C(\C)CC/C(=C/C=O)C(C)C</smiles>

4<smiles>C=C/C(C)=C\CC/C(C)=C/c1cc(C(=O)OCC)co1</smiles>

Figure 5 Chemical structures of the dereplicated metabolites from Nephthea sp. (Stereochemistry was shown as predicted from MarinLit).

alcohols and phenols. Another absorption band at $2083.12 \mathrm{~cm}^{-1}$ could be assigned for the triple bond stretching. Moreover, the absorption band at $1913.39 \mathrm{~cm}^{-1}$ was characteristic for an allene group, whereas the absorption bands $1643.35,1635.64 \mathrm{~cm}^{-1}$

Table I In vitro COX-I and COX-2 Inhibitory Activities of the Crude Extract and Different Fractions of Nephthea Sp., Along with Their Selectivity Ratio

\begin{tabular}{|c|c|c|c|}
\hline Extract/Fraction & $\begin{array}{l}\text { COX-I (IC } C_{50} \text { in } \\
\mu g / m L)\end{array}$ & $\begin{array}{l}\left(\left(C O X-2\left(I_{50}\right.\right.\right. \\
\text { in } \mu g / m L)\end{array}$ & $\begin{array}{l}\text { Selectivity } \\
\text { Ratio } \\
(\text { COX2/ } \\
\text { coXI)) }\end{array}$ \\
\hline Total extract & 33.72 & 46.75 & 1.38 \\
\hline $\begin{array}{l}\text { Petroleum ether } \\
\text { fraction }\end{array}$ & 381.96 & 27.43 & 0.07 \\
\hline $\begin{array}{l}\text { Ethyl acetate } \\
\text { fraction }\end{array}$ & 100.51 & 141.20 & 1.40 \\
\hline $\mathrm{n}$-Butanol fraction & 254.66 & 39.33 & 0.15 \\
\hline Acetone fraction & 399.69 & 36.15 & 0.09 \\
\hline $\begin{array}{l}\text { Petroleum ether } \\
\text { nano fraction }\end{array}$ & $494.20 \pm 16.34$ & $3.34 \pm 0.19$ & 147.96 \\
\hline $\begin{array}{l}\text { Ethyl acetate nano } \\
\text { fraction }\end{array}$ & $714.47 \pm 22.59$ & $4.53 \pm 0.24$ & $|57.7|$ \\
\hline $\mathrm{AgNO}_{3}$ & $249.86 \pm 9.26$ & $4.38 \pm 0.26$ & 57.04 \\
\hline Celecoxib & 119.97 & 5.63 & 0.04 \\
\hline Indomethacin & 127.57 & 52.24 & 0.40 \\
\hline
\end{tabular}

could be assigned for alkene stretching. The absorption band at $1392.61 \mathrm{~cm}^{-1}$ was also characteristic for $\mathrm{C}-\mathrm{C}$ stretching in aromatic rings, while those at 1284.59 and $1246.02 \mathrm{~cm}^{-1}$ were distinctive for $\mathrm{C}-\mathrm{O}$ stretching of aromatic esters. Furthermore, the absorption bands at

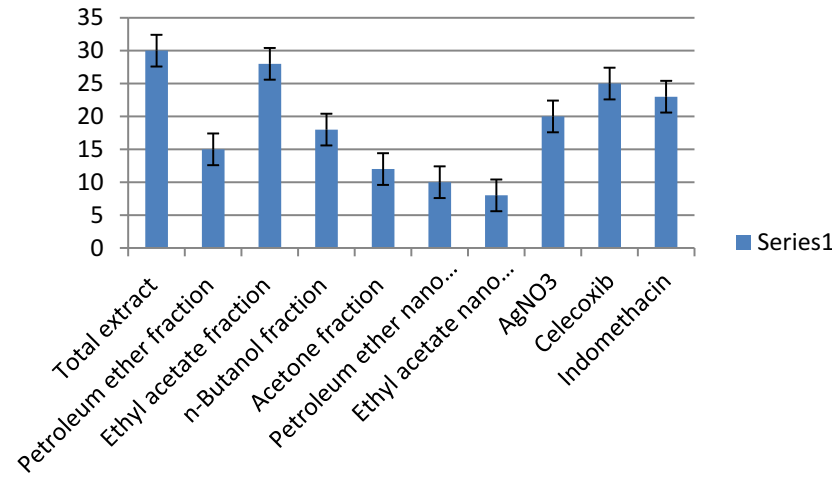

Figure 6 In-vitro anti-COX-I potential of the tested samples.
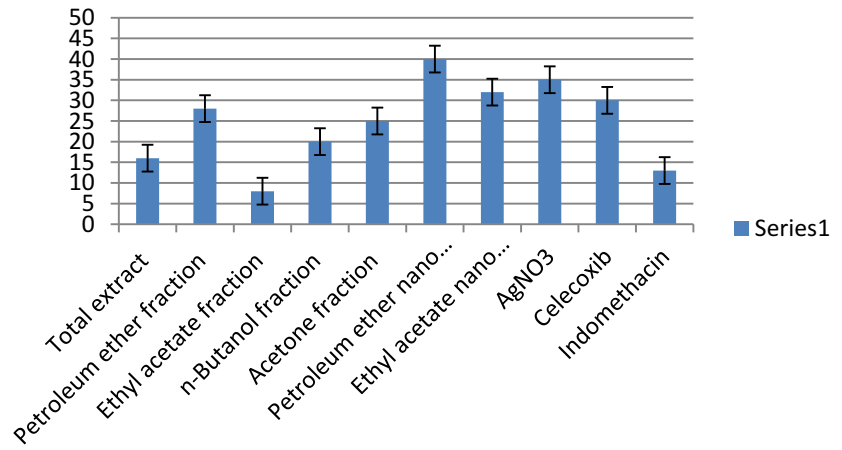

Figure 7 In-vitro anti-COX-2 potential of the tested samples. 

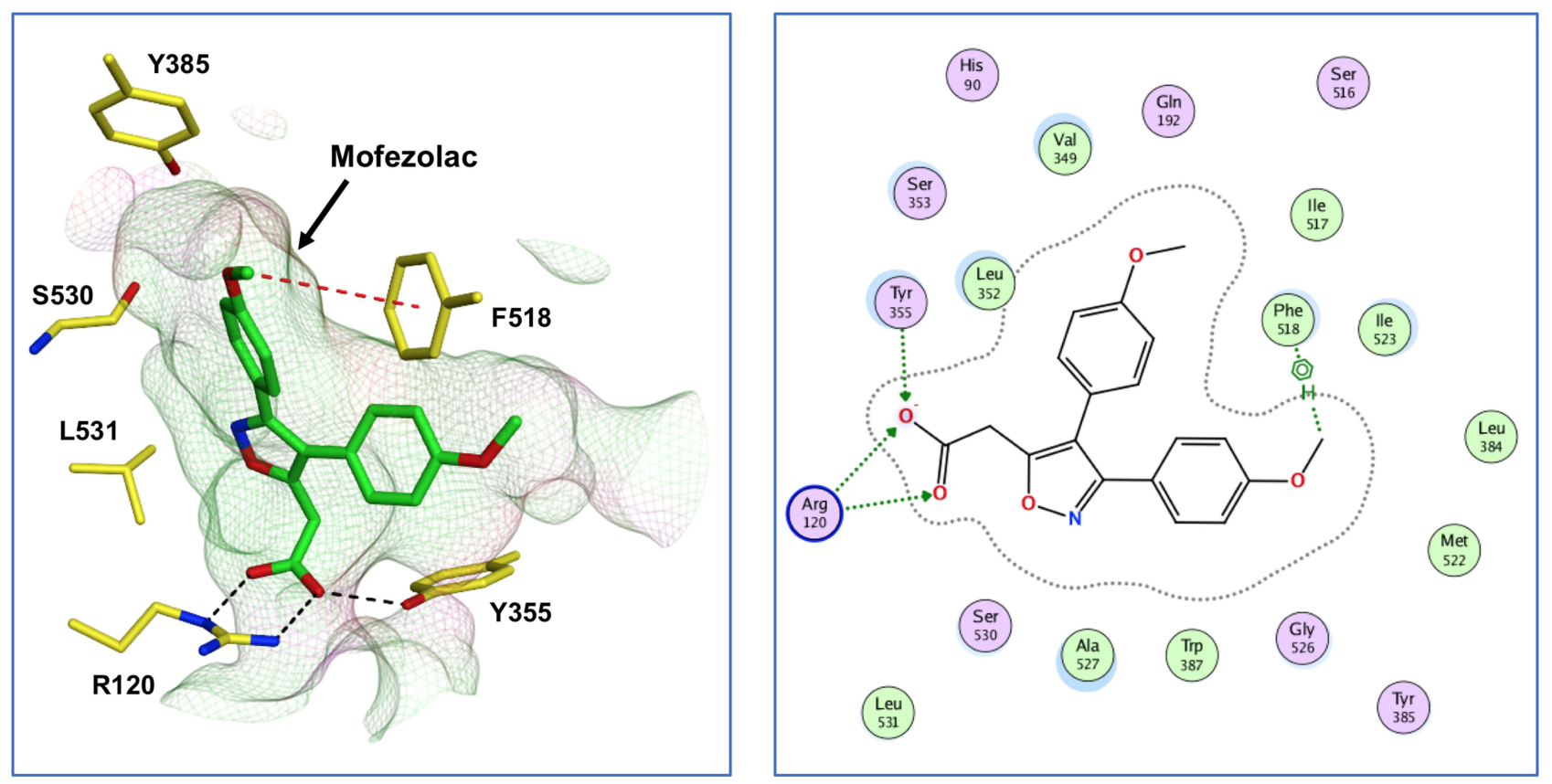

Figure $83 D$ and 2D plots of the poses of Mofezolac in the binding pocket of COX-I.
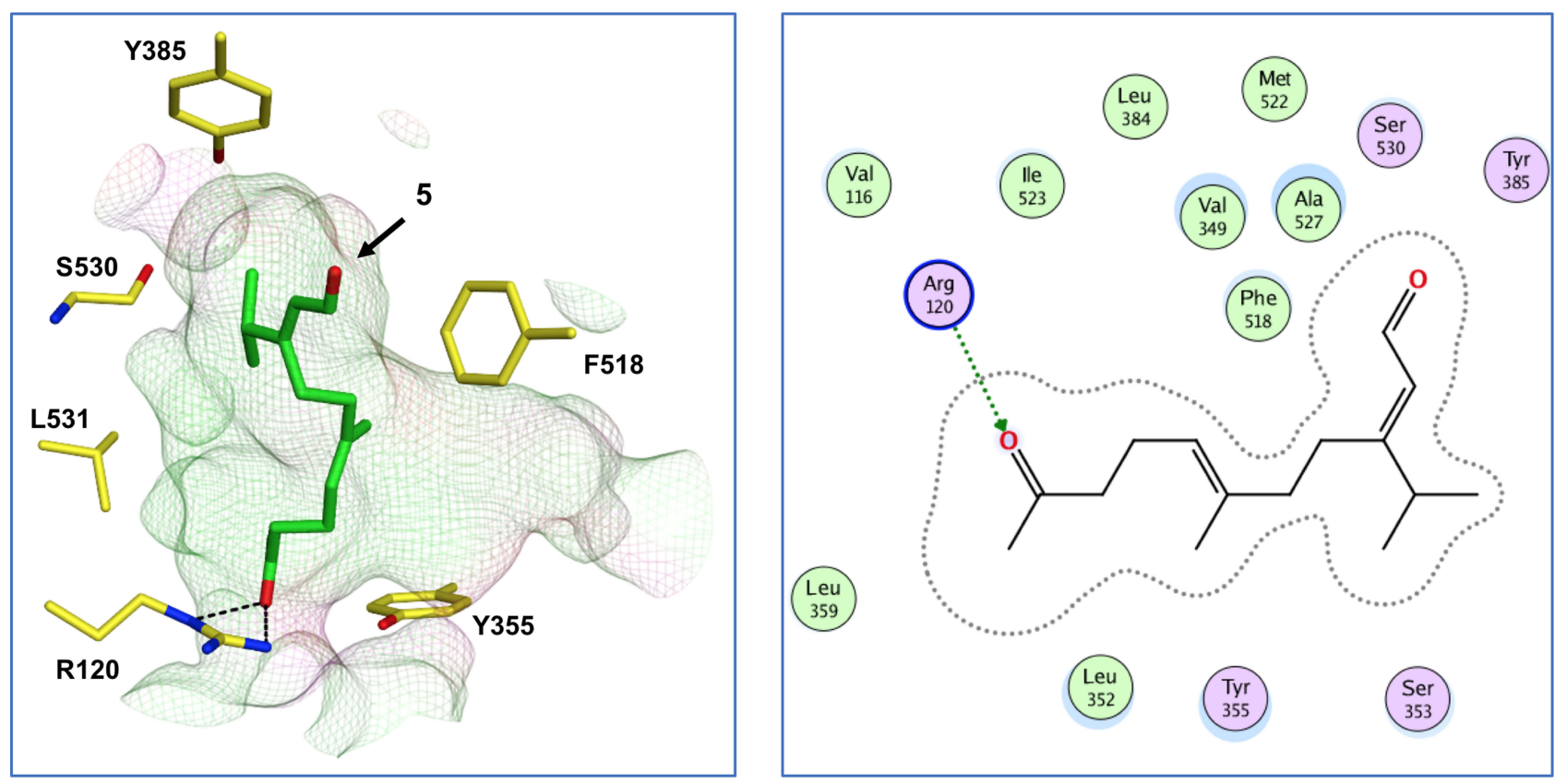

Figure $93 \mathrm{D}$ and 2D plots of the poses of compound 5 in the binding pocket of COX-I.

1222.87 and $1076.28 \mathrm{~cm}^{-1}$ were typical for $\mathrm{C}-\mathrm{O}$ stretching of secondary and primary alcohols, ${ }^{65-67}$ respectively. In this regard, the observed absorption bands in the FTIR analysis could be mainly attributed to terpenoids having the main functional groups, including ketones, aldehydes, carboxylic acids, and others. Such bioactive metabolites interact with metal ions $\left(\mathrm{Ag}^{+}\right)$through these functional groups, mediating their reduction to nanoparticles $\left(\mathrm{Ag}^{0}\right)$ and increasing the stability of the resulting nanoparticles. ${ }^{64,68}$ 

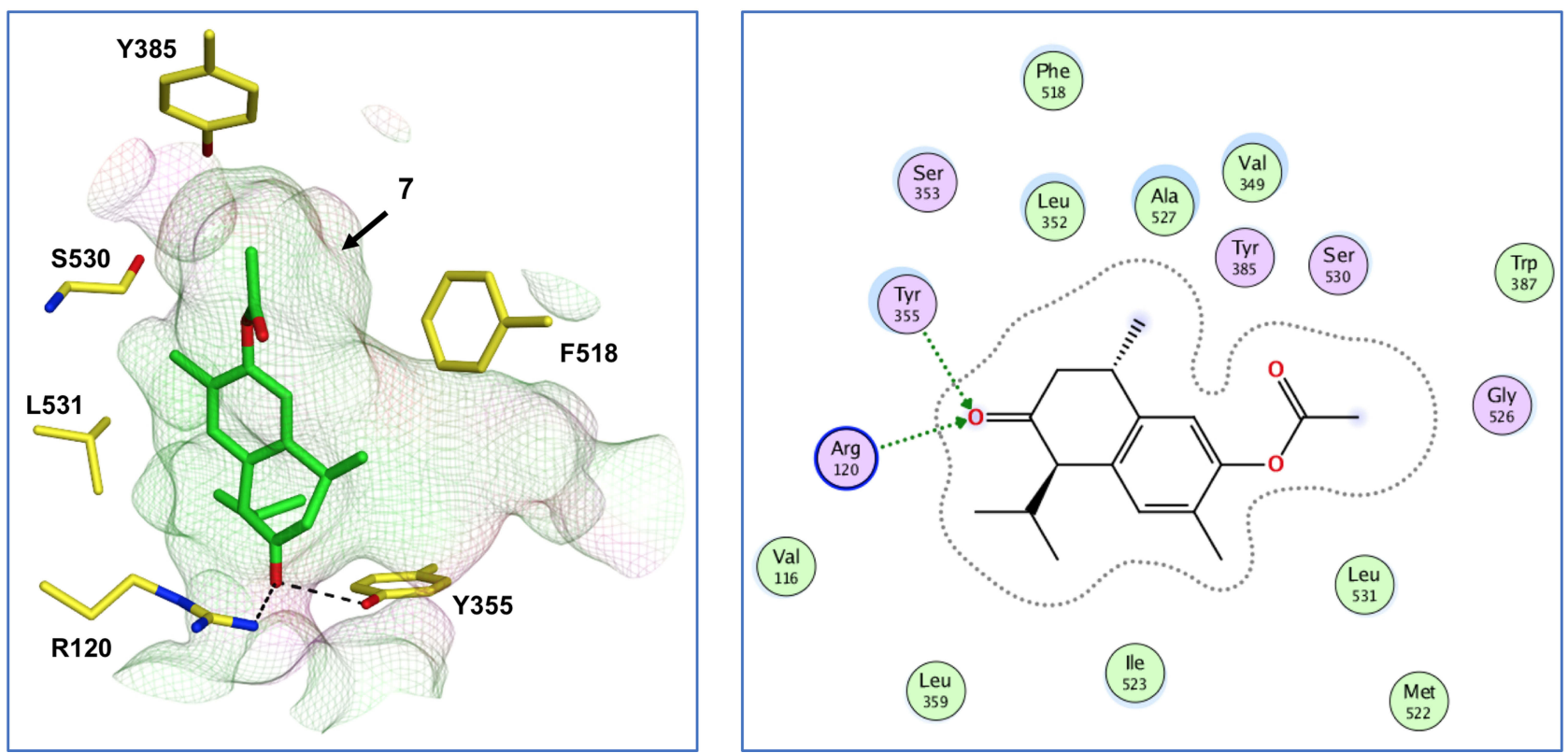

Figure $103 D$ and 2D plots of the poses of compound 7 in the binding pocket of COX-I.
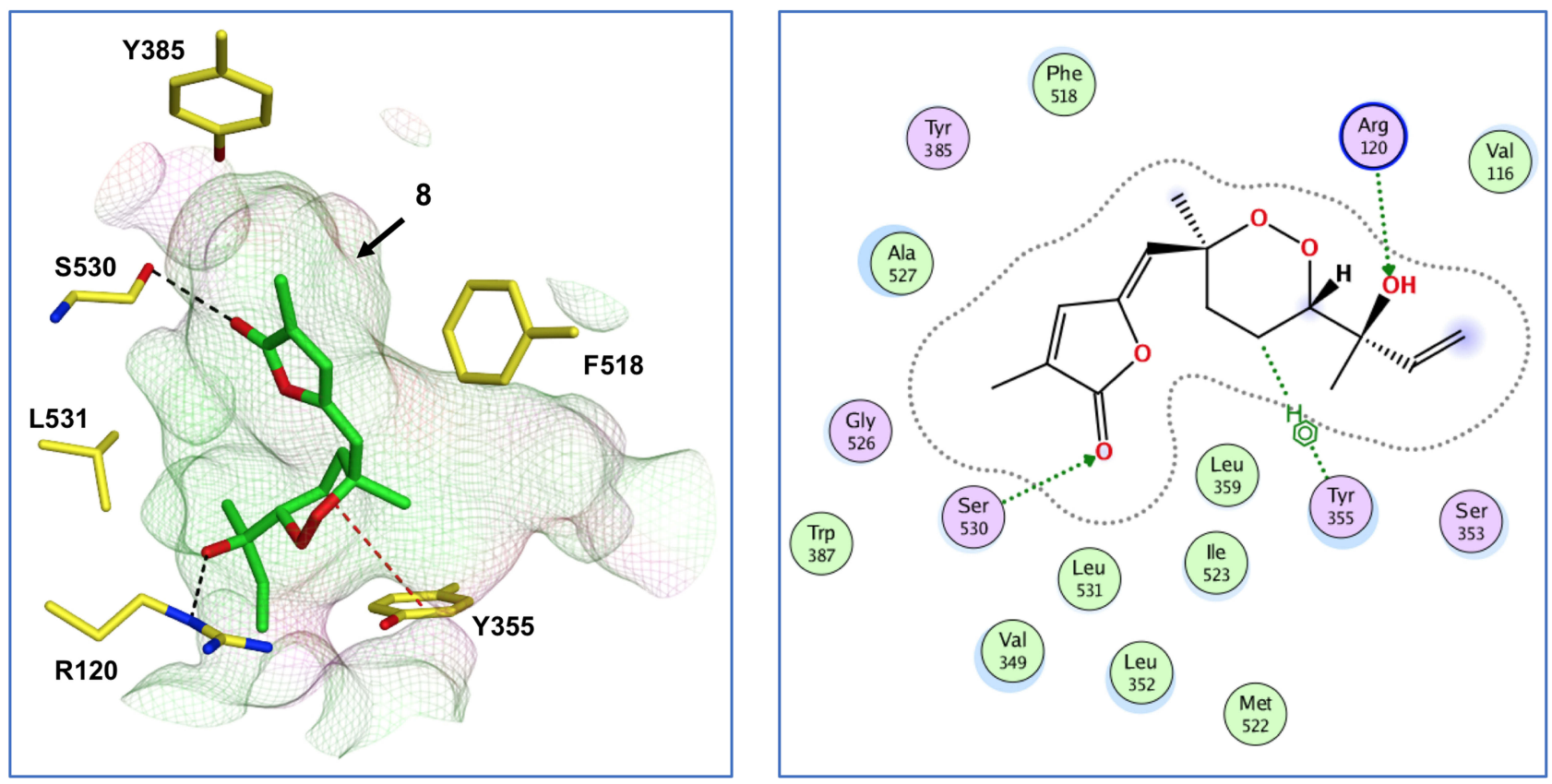

Figure II 3D and 2D plots of the poses of compound 8 in the binding pocket of COX-I.

Determination of the Nanoparticles

Particle Size Distribution (Z-Average Mean) of the Pet. Ether and Ethyl Acetate Samples of Nephthea Sp. SNPs

The z-average mean (d.nm) in case of pet. ether nano extract was 157 with a polydispersity index (PDI) 0.490 and in case of ethyl acetate nano extract with the z-average is 178.3 with a polydispersity index (PDI) 0.451 . The morphology and dimensions of the biosynthesized SNPs were initially characterized using TEM image as shown in (Figure 1A and B) with an average size ranging from $8.34 \mathrm{~nm}$ to $11.19 \mathrm{~nm}$. Additionally, the mean particle size determined by TEM analysis was significantly smaller than that measured by 

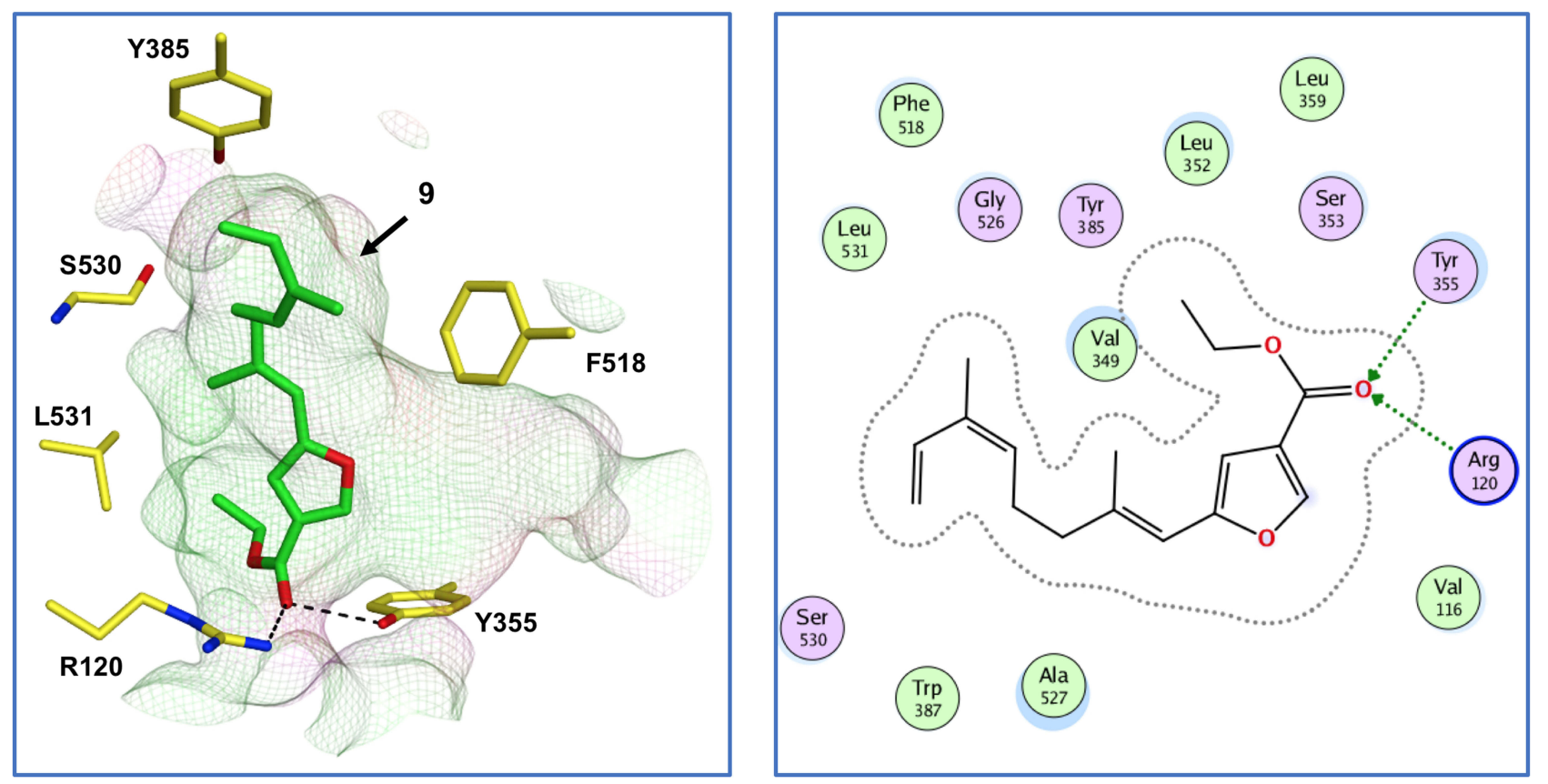

Figure $123 D$ and 2D plots of the poses of compound 9 in the binding pocket of COX-I.
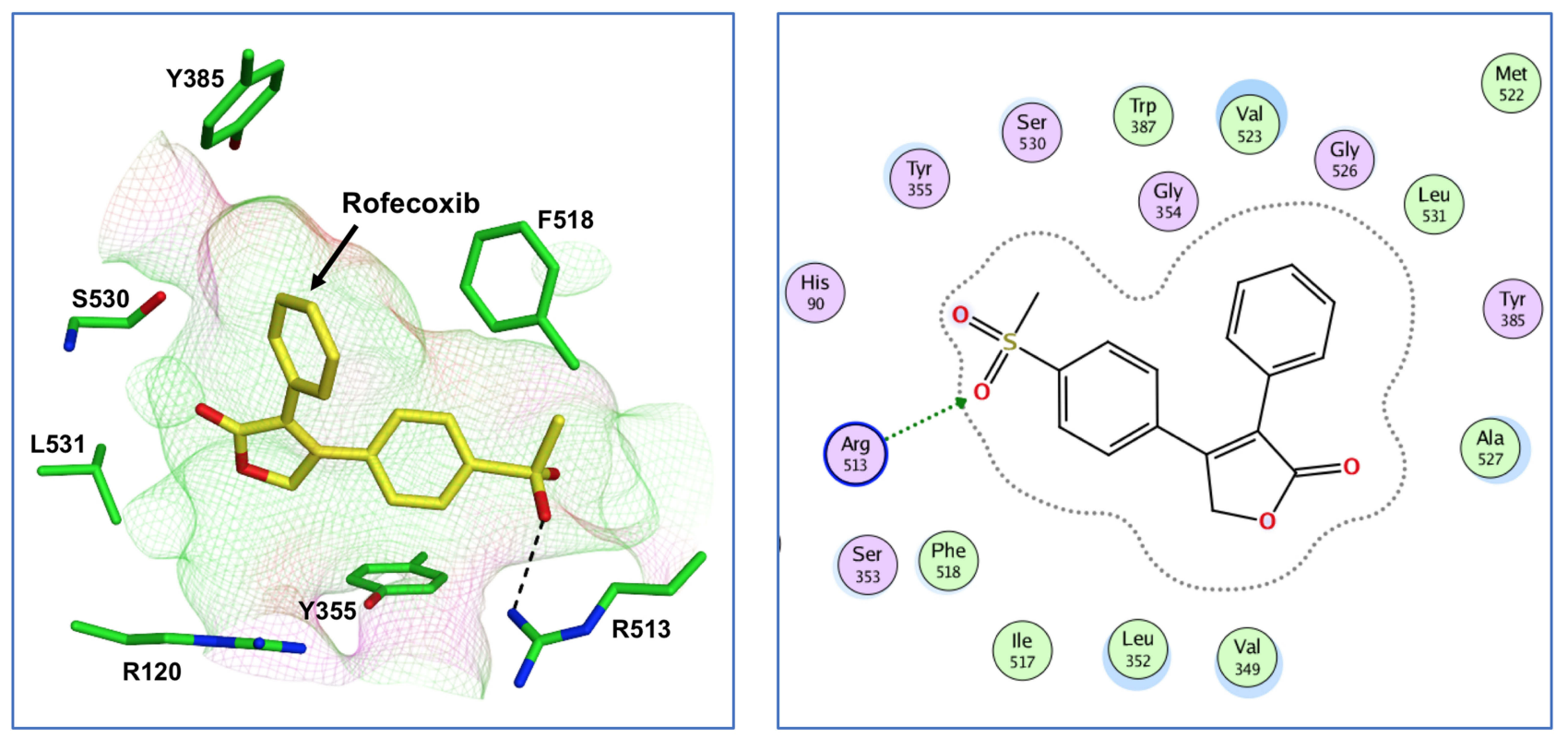

Figure $133 \mathrm{D}$ and 2D plots of the poses of Rofexocib in the binding pocket of COX-2.

DLS analysis (Figure 1A and B \& Figure 4A and B). This could be possibly due to the adsorption of organic stabilizers from the extract on the surface of SNPs and the aggregation of some small particles. ${ }^{69}$

\section{Metabolomics Profiling of the Soft Coral Nephthea Sp}

Metabolomics analysis of Nephthea sp. using LC-HR-ESIMS for dereplication purposes has resulted in the identification of a range of diverse secondary metabolites that were dominated by sesquiterpenoids. The detected compounds (Figure 5, Table S1) were identified by coupling MZmine with some databases, namely Marinlit and DNP. In view of that, the mass ion peak at $\mathrm{m} / \mathrm{z} 175.112$ for the suggested molecular formula $\mathrm{C}_{12} \mathrm{H}_{16} \mathrm{O}$ was identified as (4aS, 8S)-5, 6, 7, 8-tetrahydro-4a, 8-dimethylnaphthalen-2(4aH)-one (1). This trinorudesmadienone sesquiterpene was previously reported from the soft coral $N$. erecta. ${ }^{70}$ Moreover, the mass ion peak at $\mathrm{m} / \mathrm{z}$ 

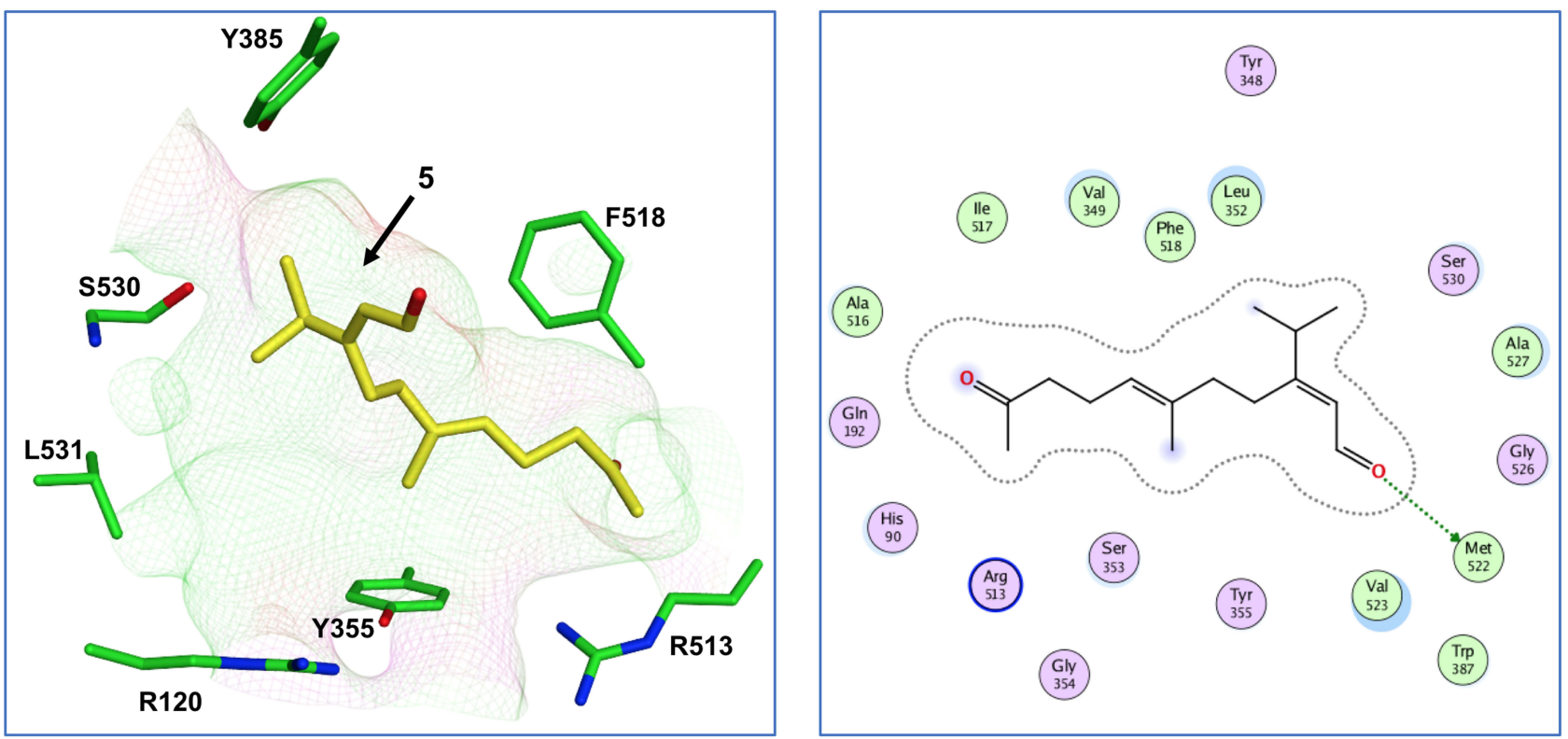

Figure $143 \mathrm{D}$ and 2D plots of the poses of compound 5 in the binding pocket of COX-2.
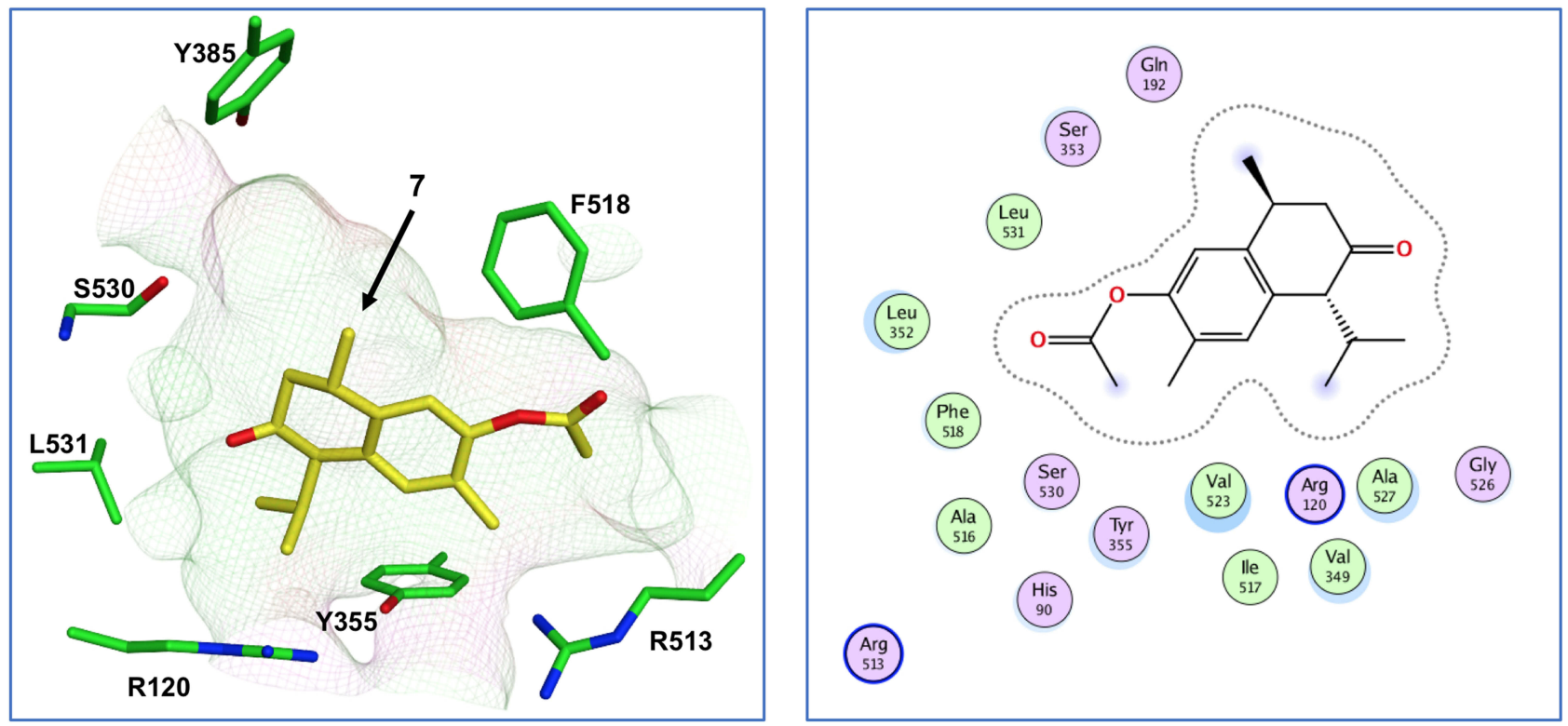

Figure $153 D$ and $2 \mathrm{D}$ plots of the poses of compound 7 in the binding pocket of COX-2.

215.144 for the predicted molecular formula $\mathrm{C}_{15} \mathrm{H}_{18} \mathrm{O}$ was also dereplicated as the germacrane sesquiterpene furanotriene (2), which was formerly obtained from the Formosan soft coral Lemnalia sp. ${ }^{71}$ Another mass ion peak at $\mathrm{m} / \mathrm{z} 217.159$, corresponding to the molecular formula $\mathrm{C}_{15} \mathrm{H}_{22} \mathrm{O}$ was dereplicated as (+)-cyclocolorenone (3). This tricyclic sesquiterpene was earlier isolated from different members of the genus Nephthea, eg, N. chabrolii AUDOIN. ${ }^{72}$ Additionally, another nardosinane sesquiterpene with the molecular formula $\mathrm{C}_{15} \mathrm{H}_{22} \mathrm{O}_{2}$, in good agreement with the mass ion peak at $\mathrm{m} / \mathrm{z} 233.154$, was characterized as lemnalactone (4). This compound was firstly identified from the soft coral Paralemnalia digitiformis Macfadyen. ${ }^{73}$ Similarly, a sec-germacrane sesquiterpene was dereplicated as $(2 E, 6 E)$-3-isopropyl-6-methyl-10-oxoundec2,6-dienal (5), in conformity with the mass ion peak at $\mathrm{m} / \mathrm{z}$ 235.170 and the molecular formula $\mathrm{C}_{15} \mathrm{H}_{24} \mathrm{O}_{2}$. This molecule was reported formerly from the soft coral $N$. erecta. ${ }^{26}$

Furthermore, the mass ion peak at $\mathrm{m} / \mathrm{z} 251.127$, corresponding to the suggested molecular formula $\mathrm{C}_{14} \mathrm{H}_{20} \mathrm{O}_{4}$, was characterized as 1(10)-epoxy-2-hydroxy-12-nornardosin-7,11- 

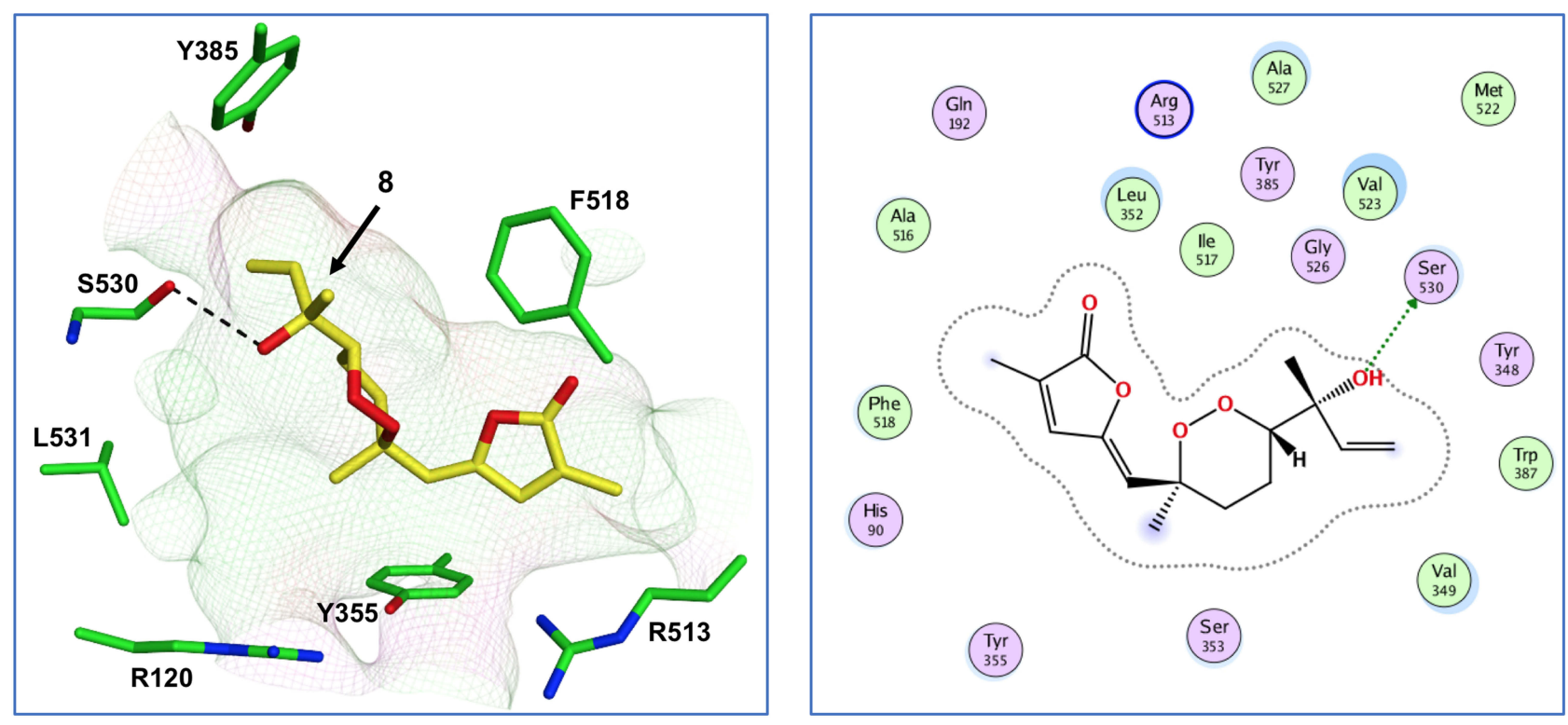

Figure $163 \mathrm{D}$ and 2D plots of the poses of compound 8 in the binding pocket of COX-2.
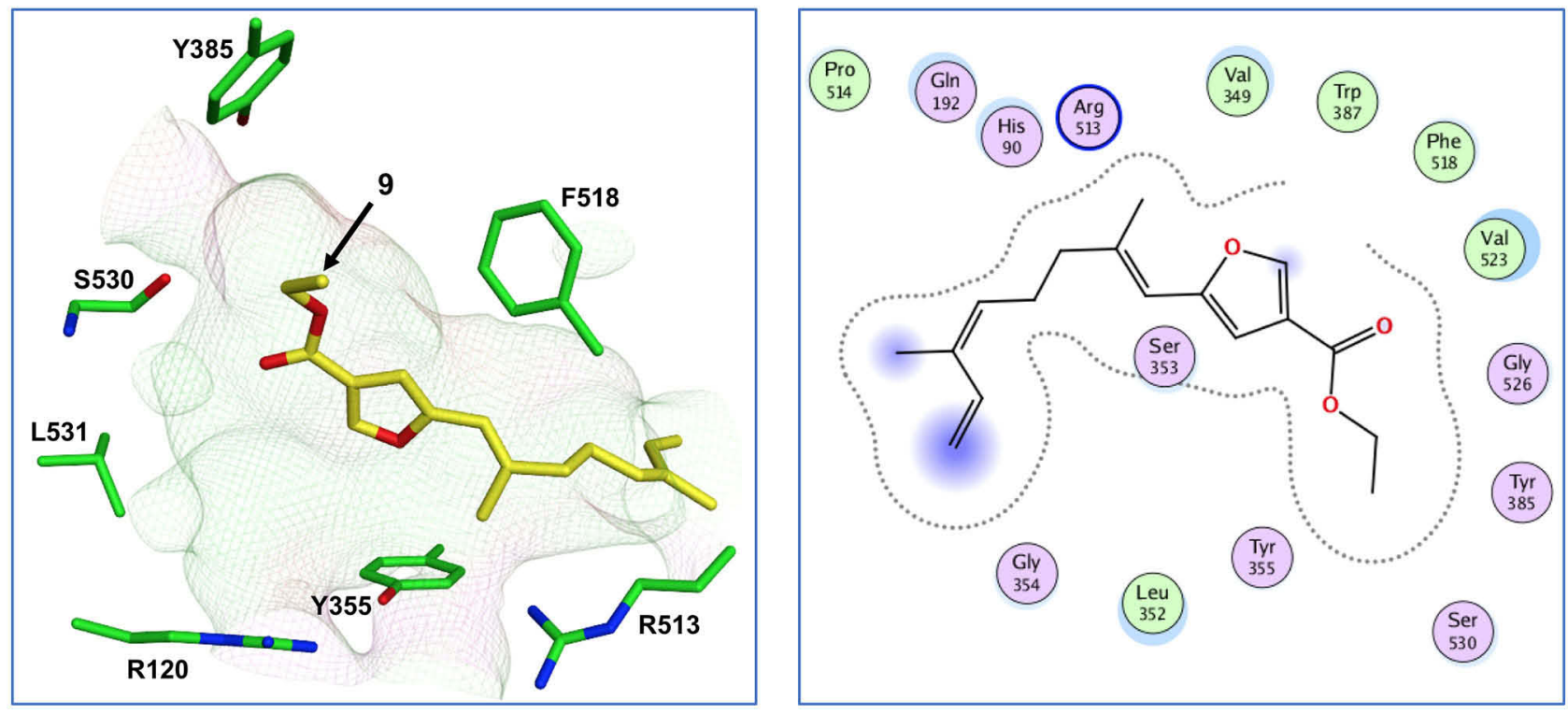

Figure $173 \mathrm{D}$ and 2D plots of the poses of Sinularioperoxide $E$ in the binding pocket of COX-2.

dione (6), a sesquiterpene that was previously obtained from the genus Lemnalia, eg, L. africana May, which belongs to the family Nephtheidae. ${ }^{74}$ Another compound was dereplicated as 7-acetoxycalamenen-3-one (7) on account of the observed mass ion peak at $\mathrm{m} / \mathrm{z} 273.148$, and in accordance with the molecular formula $\mathrm{C}_{17} \mathrm{H}_{22} \mathrm{O}_{3}$. This sesquiterpene was also formerly reported from Lemnalia cervicornis May. ${ }^{75}$ In addition to the aforementioned sesquiterpenes, a furanocarboxylate derivative, namely ethyl 5-[(1E, 5Z)-2, 6-dimethylocta-1, 5, 7trienyl] furan-3-carboxylate (8), was dereplicated from the mass ion peak at $\mathrm{m} / \mathrm{z} 275.163$, in consonance with the molecular formula $\mathrm{C}_{16} \mathrm{H}_{22} \mathrm{O}_{5}$. This molecule was formerly obtained from the soft corals Sinularia gonatodes Kolonko ${ }^{76}$ and Capnella fungiform Kükenthal. ${ }^{77}$ Additionally, the mass ion peak at $\mathrm{m} / \mathrm{z} 281.138$, in keeping with the molecular formula $\mathrm{C}_{15} \mathrm{H}_{20} \mathrm{O}_{5}$, was dereplicated as the sesquiterpene sinularioperoxide E (9), which was purified from Sinularia sp. $^{78}$ Additionally, a cembrane diterpenoid compound with the molecular formula $\mathrm{C}_{20} \mathrm{H}_{24} \mathrm{O}_{3}$ was characterized as rubifolide (10) from the mass ion peak at $\mathrm{m} / \mathrm{z} 313.164$. It was also 
previously isolated from the soft coral Gersemia rubiformis Ehrenberg. ${ }^{79}$

\section{Anti-Inflammatory Activity}

Soft corals of the genus Nephthea have been regarded as a pool of a diverse array of secondary metabolites, of which steroids and terpenoids were reported to prevail. ${ }^{80}$ Studies have also shown that these metabolites markedly contribute to the promising anti-inflammatory potential of these soft corals. ${ }^{81}$ In this respect, the ability of the total extract and different fractions of Nephthea sp., to inhibit the enzymatic activity of COX-1 and COX-2 was evaluated. The potency ( $\mathrm{IC}_{50}$ values) of the tested samples was determined and compared to those of the reference drugs; celecoxib and indomethacin. As shown in Table 1, Figures 6 and 7, the obtained results revealed that some of the tested samples exhibited inhibitory activities towards the isoforms of COX enzyme. Among them, only the total extract of Nephthea sp. showed COX-1 inhibitory potential with an $\mathrm{IC}_{50}$ value of $33.72 \mu \mathrm{g} / \mathrm{mL}$, which is more potent than celecoxib and indomethacin, whereas the petroleum ether, ethyl acetate, n-butanol, and acetone fractions exhibited weak activities $\left(\mathrm{IC}_{50}>100 \mu \mathrm{g} / \mathrm{mL}\right)$. On the other hand, the petroleum ether fraction displayed the maximum inhibitory actions against COX-2 compared to indomethacin, with an $\mathrm{IC}_{50}$ value of $27.43 \mu \mathrm{g} / \mathrm{mL}$, followed by the acetone and n-butanol fractions, and the total extract, whereas the ethyl acetate fraction exhibited a weak activity against COX-2 $\left(\mathrm{IC}_{50}>100 \mu \mathrm{g} / \mathrm{mL}\right)$.

In the same context, the anti-inflammatory potential of the green synthesize SNPs of the petroleum ether and ethyl acetate fractions were investigated. The petroleum ether fraction demonstrated more potent COX-2 inhibitory actions with an $\mathrm{IC}_{50}$ value of $3.34 \mu \mathrm{g} / \mathrm{mL}$, followed by the ethyl acetate fraction with $\mathrm{IC}_{50}$ of $4.53 \mu \mathrm{g} / \mathrm{mL}$. In terms of $\mathrm{IC}_{50}$ values, both the tested nanosamples showed higher inhibitory activities against COX-1 and COX-2 enzymes than the reference anti-inflammatory drugs; celecoxib and indomethacin with $\mathrm{IC}_{50}$ values of $119.97,5.63$, 127.57 and $52.24 \mu \mathrm{g} / \mathrm{mL}$, respectively.

Since NPs have a large surface area to volume ratio, it is supposed that they are better at blocking pro-inflammatory cytokines and inflammation assisting enzymes when compared to their bulk samples. Moreover, Ag NPs suppress production of pro-inflammatory cytokines like IL-12 and TNF- $\alpha$ and also cause a reduction in COX-2 gene expression at higher concentrations which assist in achieving its anti- inflammatory potential. ${ }^{49}$ To the best of our knowledge, and based on the available literature survey, this work represents the first study of the anti-inflammatory potential of green synthesized silver nanoparticles using soft corals.

\section{Molecular Docking Study}

On account of the interesting results of the in vitro study on the anti-inflammatory potential of Nephthea sp., which revealed the direct inhibition of both COX-1 and COX-2, an in silico study was performed to investigate which compounds have the potential to bind in the active sites of these $\mathrm{COX}$ isoforms. Molecular docking of the dereplicated compounds (1-10) from this soft coral into both COX-1 and COX-2 has successfully predicted the active compounds and their binding mode within the active sites of both isozymes. The binding free energy $(\Delta \mathrm{G})$ in $\mathrm{kcal} / \mathrm{mol}$ of the characterized compounds to COX-1 and COX-2 in comparison with the co-crystallized ligands is summarized in Table S2. Compounds 5 and 7-9 showed higher binding affinities to both COX isozymes, while the other compounds revealed weak to medium affinities. Interestingly, both compound $\mathbf{5}$ and mofezolac displayed high and comparable binding affinities to COX-1 protein. These results may suggest that compound $\mathbf{5}$ is the main chemical principle responsible for the anti-COX-1 properties of Nephthea sp. On the contrary, compounds 5 as well as 7-9 exhibited noticeable affinities to COX-2 protein, proposing that more compounds could be adapted in COX-2 than in COX-1 due to the larger active site of COX-2 and its higher hydrophobic nature as compared with COX-1. Likewise, the smaller size of COX-1 pocket compared to the molecular volume of compound $\mathbf{3}$ did not allow this molecule to be docked to the COX-1 active site.

Figures 8-12 illustrates the binding mode and orientation of the high-affinity compounds (5 and 7-9) within the active site of COX-1. All of these compounds formed at least one hydrogen bond with the key amino acid residue (Arg120). Compound 5 showed the highest binding affinity due to its capacity to form two strong hydrogen bonds with the essential amino acid residue (Arg120) in a similar manner to the cocrystalized ligand (Mofezolac). Moreover, the high binding affinities of compounds $\mathbf{7}$ and $\mathbf{9}$ could be explained by their ability to make an additional stronger hydrogen bond with the key amino acid Tyr355. Nonetheless, the moderate binding affinity of compound $\mathbf{8}$ could be rationalized by its capability to make one more hydrogen bond but with the non-essential amino acid Ser530, in addition to a $\mathrm{CH}-\pi$ interaction with the key residue Tyr355. 
Figures 13-17 demonstrates the binding mode and orientation of the high-affinity compounds (5 and 7-9) within the active site of COX-2. All compounds were able to occupy the selectivity pocket of COX-2, but in different degrees and orientations. Such differences were attributed to their differences in hydrophobicity. The fact that Rofecoxib makes only one hydrophilic interaction and 41 hydrophobic contacts with the active site of COX-2 could illustrate their relative affinities to COX-2 protein. ${ }^{57}$ Briefly, compound $\mathbf{8}$ showed a moderate affinity to COX-2 due to its less hydrophobic nature. Conversely, the other active compounds $(\mathbf{5}, \mathbf{7}$, and 9) are more hydrophobic, and consequently, have more binding affinities to COX-2 than compound $\mathbf{8}$.

Taking all together, the results of the docking analysis suggested that compounds $\mathbf{5}$ and 7-9 are more likely responsible for the anti-inflammatory activity of the soft coral through their anti-COX activity.

\section{Conclusion}

The present study demonstrated a simple green method for the synthesis of SNPs using the petroleum ether and ethyl acetate fractions of the soft coral Nephthea sp. The petroleum ether nano fraction was the most potent COX-2 inhibitor, followed by the ethyl acetate nano fraction. Additionally, the antiinflammatory potential of the total extract and its derived fractions were investigated showing that the petroleum ether and acetone fractions possess the highest COX-2 inhibitory activities, whereas the total extract showed potent COX-1 inhibitory potential. LC-MS based metabolomics was also applied in unveiling the chemical complexity of marine invertebrates, typified by metabolic profiling of the under investigated soft coral Nephthea sp., resulting in the characterization of a group of sesquiterpenes and other metabolites of different structural types. Molecular docking studies of the identified metabolites have pinpointed that compounds $(2 E, 6 E)$-3-isopropyl-6-methyl-10-oxoundec-2,6-dienal (5), 7-acetoxycalamenen-3-one (7), ethyl 5-[(1E, 5Z)-2, 6-dimethylocta-1, 5, 7trienyl] furan-3-carboxylate (8), and sinularioperoxide $\mathrm{E}(9)$, which were detected at high levels in the petroleum ether, ethyl acetate, and acetone fractions, possess the best COX binding aptitude, suggesting their probable responsibility for the observed COX inhibitory potential of Nephthea sp. In view of that, synthesis of silver nanoparticles using natural resources is a better alternative to the chemical synthesis as it is ecofriendly, less toxic for human health and environment with nearly no adverse effect. Additionally, from the previous results of our research, one can affirm that Nephthea sp. can play an important role in the bioreduction and stabilization of silver nanoparticles. Moreover, this soft coral could be regarded as a considerable and interesting pool of bioactive metabolites for the development of potent natural anti-inflammatory remedies.

\section{Acknowledgments}

The APC was funded by the open access publication fund of the Technical University of Dresden (TU Dresden). The authors gratefully acknowledge Khayrya A Youssif, Department of Pharmacognosy, Faculty of Pharmacy, Modern University for Technology and Information, Cairo, Egypt, for helping us in performing green synthesis of nanoparticles.

\section{Disclosure}

The authors report no conflicts of interest in this work.

\section{References}

1. Putra MY, Murniasih T. Marine soft corals as source of lead compounds for anti-inflammatories. J Coast Life Med. 2016;4:73-77. doi:10.12980/jclm.4.2016j5-226

2. Hanaoka BY, Ithurburn MP, Rigsbee CA, et al. Chronic inflammation in rheumatoid arthritis and mediators of skeletal muscle pathology and physical impairment: a review. Arthritis Care Res. 2019;71 (2):173-177. doi:10.1002/acr.23775

3. Geovanini GR, Libby P. Atherosclerosis and inflammation: overview and updates. Clin Sci. 2018;132(12):1243-1252. doi:10.1042/ CS20180306

4. Biondi-Zoccai GG, Abbate A, Liuzzo G, Biasucci LM. Atherothrombosis, inflammation, and diabetes. $\mathrm{J} \mathrm{Am} \mathrm{Coll} \mathrm{Cardiol.}$ 2003;41(7):1071-1077. doi:10.1016/S0735-1097(03)00088-3

5. Akiyama $\mathrm{H}$, Barger $\mathrm{S}$, Barnum $\mathrm{S}$, et al. Inflammation and Alzheimer's disease. Neurobiol Aging. 2000;21(3):383-421. doi:10.1016/S0197-4580(00)00124-X

6. Cross RK, Wilson KT. Nitric oxide in inflammatory bowel disease. Inflamm Bowel Dis. 2003;9(3):179-189. doi:10.1097/00054725200305000-00006

7. Coussens LM, Werb Z. Inflammation and cancer. Nature. 2002;420 (6917):860. doi:10.1038/nature01322

8. Siracusa MC, Kim BS, Spergel JM, Artis D. Basophils and allergic inflammation. $J$ Allergy Clin Immunol. 2013;132(4):789-801. doi:10.1016/j.jaci.2013.07.046

9. Leliefeld PH, Wessels CM, Leenen LP, Koenderman L, Pillay J. The role of neutrophils in immune dysfunction during severe inflammation. Critical Care. 2016;20(1):73. doi:10.1186/s13054-016-1250-4

10. Geering B, Stoeckle C, Conus S, Simon H-U. Living and dying for inflammation: neutrophils, eosinophils, basophils. Trends Immunol. 2013;34(8):398-409. doi:10.1016/j.it.2013.04.002

11. Rai M, Deshmukh S, Ingle A, Gade A. Silver nanoparticles: the powerful nanoweapon against multidrug-resistant bacteria. $J$ Appl Microbiol. 2012;112(5):841-852. doi:10.1111/j.1365-2672.2012.05253.x

12. Cavalcante-Silva LHA, Barbosa Brito da Matta C, de Araújo MV, et al. Antinociceptive and anti-inflammatory activities of crude methanolic extract of red alga Bryothamnion triquetrum. Mar Drugs. 2012;10(9):1977-1992. doi:10.3390/md10091977

13. Saag KG, Furst DE. Major Side Effects of Systemic Glucocorticoids. 2013. 
14. Oray M, Abu Samra K, Ebrahimiadib N, Meese H, Foster CS. Longterm side effects of glucocorticoids. Expert Opin Drug Saf. 2016;15 (4):457-465. doi:10.1517/14740338.2016.1140743

15. Sostres C, Gargallo CJ, Arroyo MT, Lanas A. Adverse effects of nonsteroidal anti-inflammatory drugs (NSAIDs, aspirin and coxibs) on upper gastrointestinal tract. Best Pract Res Clin Gastroenterol. 2010;24(2):121-132. doi:10.1016/j.bpg.2009.11.005

16. Wargasetia TL, Widodo N. The link of marine products with autophagyassociated cell death in cancer cell. Current Pharmacol Rep. 2019;1-8.

17. Puttaswamygowda GH, Olakkaran S, Antony A, Purayil AK. Present status and future perspectives of marine actinobacterial metabolites. Recent Develop Applied Microbiol Biochem. 2019;307-319.

18. Gerwick WH, Moore BS. Lessons from the past and charting the future of marine natural products drug discovery and chemical biology. Chem Biol. 2012;19(1):85-98. doi:10.1016/j.chembiol.2011.12.014

19. Shady N, Fouad M, Salah Kamel M, Schirmeister T, Abdelmohsen U. Natural Product Repertoire of the Genus Amphimedon. Mar Drugs. 2019;17(1):19. doi:10.3390/md17010019

20. Wu Q, Ye F, Li X-L, et al. Uncommon polyoxygenated sesquiterpenoids from South China sea soft coral Lemnalia flava. J Org Chem. 2019;84(6):3083-3092. doi:10.1021/acs.joc.8b02912

21. Rodrigues IG, Miguel MG, Mnif W. A brief review on new naturally occurring cembranoid diterpene derivatives from the soft corals of the genera Sarcophyton, Sinularia, and Lobophytum since 2016. Molecules. 2019;24(4):781. doi:10.3390/molecules24040781

22. Zhang Q, Liang L-F, Miao Z-H, Wu B, Guo Y-W. Cytotoxic polyhydroxylated steroids from the South China Sea soft coral Lobophytum sp. Steroids. 2019;141:76-80. doi:10.1016/j.steroids.2018.11.015

23. Gong -K-K, Tang X-L, Zhang G, et al. Polyhydroxylated steroids from the South China Sea soft coral Sarcophyton sp. and their cytotoxic and antiviral activities. Mar Drugs. 2013;11(12):47884798. doi:10.3390/md11124788

24. Guibert I, Bonnard I, Pochon X, et al. Differential effects of coralgiant clam assemblages on biofouling formation. Sci Rep. 2019;9 (1):2675. doi:10.1038/s41598-019-39268-1

25. Huang H-C, Wen Z-H, Chao C-H, et al. Novel sesquiterpenoids from the Formosan soft coral Paralemnalia thyrsoides. Tetrahedron Lett. 2006;47(49):8751-8755. doi:10.1016/j.tetlet.2006.10.002

26. Cheng S-Y, Huang Y-C, Wen Z-H, et al. Novel sesquiterpenes and norergosterol from the soft corals Nephthea erecta and Nephtheachabroli. Tetrahedron Lett. 2009;50(7):802-806. doi:10.1016/j. tetlet.2008.12.002

27. Jacob M, Lopata AL, Dasouki M, Abdel Rahman AM. Metabolomics toward personalized medicine. Mass Spectrom Rev. 2019;38(3):221238. doi:10.1002/mas. 21548

28. Gonulalan EM, Nemutlu E, Bayazeid O, Koçak E, Yalçın FN, Demirezer LO. Metabolomics and proteomics profiles of some medicinal plants and correlation with BDNF activity. Phytomedicine. 2019;152920.

29. Vohsen SA, Fisher CR, Baums IB. Metabolomic richness and fingerprints of deep-sea coral species and populations. Metabolomics. 2019;15(3):34. doi:10.1007/s11306-019-1500-y

30. Baidoo EE. Microbial metabolomics: a general overview. Microbial Metabolomics. 2019;1-8.

31. Abdelmohsen U, Cheng C, Viegelmann C, et al. Dereplication strategies for targeted isolation of new antitrypanosomal actinosporins $\mathrm{A}$ and B from a marine sponge associated-Actinokineospora sp. EG49. Mar Drugs. 2014;12(3):1220-1244. doi:10.3390/md12031220

32. Park MV, Neigh AM, Vermeulen JP, et al. The effect of particle size on the cytotoxicity, inflammation, developmental toxicity and genotoxicity of silver nanoparticles. Biomaterials. 2011;32(36):98109817. doi:10.1016/j.biomaterials.2011.08.085

33. Kumar B, Smita K, Cumbal L, Debut A. Green synthesis of silver nanoparticles using Andean blackberry fruit extract. Saudi j Biol Sci. 2017;24(1):45-50. doi:10.1016/j.sjbs.2015.09.006
34. Abdel-Raouf N, Al-Enazi NM, Ibraheem IBM, Alharbi RM, Alkhulaifi MM. Biosynthesis of silver nanoparticles by using of the marine brown alga Padina pavonia and their characterization. Saudi $j$ Biol Sci. 2019;26(6):1207-1215. doi:10.1016/j.sjbs.2018.01.007

35. Kumar I, Mondal M, Sakthivel N. Green synthesis of phytogenic nanoparticles. Green Synthesis, Characterization Appl Nanoparticles. 2019:37-73.

36. Vijayan R, Joseph S, Mathew B. Green synthesis of silver nanoparticles using Nervalia zeylanica leaf extract and evaluation of their antioxidant, catalytic, and antimicrobial potentials. Particulate Sci Technol. 2019;37(7):809-819. doi:10.1080/02726351.2018.1450312

37. Verma P, Maheshwari SK. Applications of silver nanoparticles in diverse sectors. Int J Nano Dimension. 2019;10(1):18-36.

38. Gurunathan S. Rapid biological synthesis of silver nanoparticles and their enhanced antibacterial effects against Escherichia fergusonii and Streptococcus mutans. Arabian J Chem. 2019;12(2):168-180. doi:10.1016/j.arabjc.2014.11.014

39. de Aragao AP, de Oliveira TM, Quelemes PV, et al. Green synthesis of silver nanoparticles using the seaweed Gracilaria birdiae and their antibacterial activity. Arabian J Chem. 2019;12(8):4182-4188. doi:10.1016/j.arabjc.2016.04.014

40. Gulbagca F, Ozdemir S, Gulcan M, Sen F. Synthesis and characterization of Rosa canina-mediated biogenic silver nanoparticles for anti-oxidant, antibacterial, antifungal, and DNA cleavage activities. Heliyon. 2019;5(12):e02980. doi:10.1016/j.heliyon.2019.e02980

41. Siddiquee MA, Ud Din Parray M, Mehdi SH, et al. Green synthesis of silver nanoparticles from Delonix regia leaf extracts: in-vitro cytotoxicity and interaction studies with bovine serum albumin. Mater Chem Phys. 2020;242:122493. doi:10.1016/j.matchemphys.2019.122493

42. Şahin B, Aygün A, Gündüz H, et al. Cytotoxic effects of platinum nanoparticles obtained from pomegranate extract by the green synthesis method on the MCF-7 cell line. Colloids Surf B Biointerfaces. 2018;163:119-124. doi:10.1016/j.colsurfb.2017.12.042

43. Meva F, Mbeng JOA, Ebongue CO, et al. Stachytarpheta cayennensis aqueous extract, a new bioreactor towards silver nanoparticles for biomedical applications. J Biomater Nanobiotechnol. 2019;10 (02):102. doi:10.4236/jbnb.2019.102006

44. Parthiban E, Manivannan N, Ramanibai R, Mathivanan N. Green synthesis of silver-nanoparticles from Annona reticulata leaves aqueous extract and its mosquito larvicidal and anti-microbial activity on human pathogens. Biotechnol Rep. 2019;21:e00297. doi:10.1016/j. btre.2018.e00297

45. Paladini F, Pollini M. antimicrobial silver nanoparticles for wound healing application: progress and future trends. Materials. 2019;12 (16):2540. doi:10.3390/ma12162540

46. Inbakandan D, Sivaleela G, Peter DM, Kiurbagaran R, Venkatesan R, Khan SA. Marine sponge extract assisted biosynthesis of silver nanoparticles. Mater Lett. 2012;87:66-68. doi:10.1016/j. matlet.2012.07.083

47. Öztürk BY, Gürsu BY, Dağ İ. Antibiofilm and antimicrobial activities of green synthesized silver nanoparticles using marine red algae Gelidium corneum. Process Biochem. 2019.

48. Valarmathi N, Ameen F, Almansob A, Kumar P, Arunprakash S, Govarthanan M. Utilization of marine seaweed Spyridia filamentosa for silver nanoparticles synthesis and its clinical applications. Mater Lett. 2020;263:127244. doi:10.1016/j.matlet.2019.127244

49. Agarwal H, Nakara A, Shanmugam VK. Anti-inflammatory mechanism of various metal and metal oxide nanoparticles synthesized using plant extracts: A review. Biomed Pharmacother. 2019;109:25612572. doi:10.1016/j.biopha.2018.11.116

50. Shady NH, Fouad MA, Ahmed S, et al. A new antitrypanosomal alkaloid from the Red Sea marine sponge Hyrtios sp. J Antibiot. 2018;71(12):1036. doi:10.1038/s41429-018-0092-5 
51. Abdelhafez OH, Fawzy MA, Fahim JR, et al. Hepatoprotective potential of Malvaviscus arboreus against carbon tetrachlorideinduced liver injury in rats. PLoS One. 2018;13(8):e0202362. doi:10.1371/journal.pone. 0202362

52. Haggag EG, Elshamy AM, Rabeh MA, et al. Antiviral potential of green synthesized silver nanoparticles of Lampranthus coccineus and Malephora lutea. Int J Nanomed. 2019;14:6217. doi:10.2147/IJN.S214171

53. Dictionary of natural products; 2017. Available from: http://dnp. chemnetbase.com/faces/chemical/ChemicalSearch.xhtml. Accessed August 28, 2018.

54. MarinLit; 2018. Available from: http://pubs.rsc.org/marinlit/. Accessed september 15, 2018.

55. OyaUnsal-Tana K, KevserPiskinb A. Molecular modeling, synthesis and screening of some new 4-thiazolidinone derivatives with promising selective COX-2 inhibitory activity. Eur $J$ Med Chem. 2012;57:59-64. doi:10.1016/j.ejmech.2012.08.046

56. Cingolani G, Panella A, Perrone MG, et al. Structural basis for selective inhibition of Cyclooxygenase-1 (COX-1) by diarylisoxazoles mofezolac and 3-(5-chlorofuran-2-yl)-5-methyl-4-phenylisoxazole (P6). Eur J Med Chem. 2017;138:661-668. doi:10.1016/j. ejmech.2017.06.045

57. Orlando BJ, Malkowski MG. Crystal structure of rofecoxib bound to human cyclooxygenase-2. Acta Crystallographica Section F. 2016;72 (10): $772-776$.

58. Abdelbaset MS, Abdel-Aziz M, Ramadan M, et al. Discovery of novel thienoquinoline-2-carboxamide chalcone derivatives as antiproliferative EGFR tyrosine kinase inhibitors. Bioorg Med Chem. 2019;27:1076-1086. doi:10.1016/j.bmc.2019.02.012

59. Ali TF, Ciftci HI, Radwan MO, et al. New SIRT2 inhibitors: histidine-based bleomycin spin-off. Bioorg Med Chem. 2019;27:17671775. doi:10.1016/j.bmc.2019.03.003

60. Gurunathan S, Han JW, Eppakayala V, Jeyaraj M, Kim J-H. Cytotoxicity of biologically synthesized silver nanoparticles in MDA-MB-231 human breast cancer cells. Biomed Res Int. 2013;2013.

61. Ibraheem I, Abd-Elaziz B, Saad W, Fathy W. Green biosynthesis of silver nanoparticles using marine Red Algae Acanthophora specifera and its antimicrobial activity. J Nanomed Nanotechnol. 2016;7(409):2.

62. Govindaraju K, Kiruthiga V, Kumar VG, Singaravelu G. Extracellular synthesis of silver nanoparticles by a marine alga, Sargassum wightii Grevilli and their antibacterial effects. $J$ Nanosci Nanotechnol. 2009;9(9):5497-5501. doi:10.1166/jnn.2009.1199

63. Jose A, Abirami T, Kavitha V, Sellakilli R, Karthikeyan J. Green synthesis of silver nanoparticles using Asystasia gangetica leaf extract and its antibacterial activity against gram-positive and gram-negative bacteria. J Pharmacognosy Phytochem. 2018;7(1):2453-2457.

64. Ahmed S, Saifullah AM, Swami BL, Ikram S. Green synthesis of silver nanoparticles using Azadirachta indica aqueous leaf extract. $J$ Radiation Res Applied Sci. 2016;9(1):1-7. doi:10.1016/j. jrras.2015.06.006

65. Kamranifar M, Naghizadeh A. Montmorillonite nanoparticles in removal of textile dyes from aqueous solutions: study of kinetics and thermodynamics. Iranian J Chem Chem Eng. 2017;36(6):127-137.

66. Wang Y, He Z, Gupta KM, Shi Q, Lu R. Molecular dynamics study on water desalination through functionalized nanoporous graphene. Carbon. 2017;116:120-127. doi:10.1016/j.carbon.2017.01.099
67. Naghizadeh A, Gholami K. Bentonite and montmorillonite nanoparticles effectiveness in removal of fluoride from water solutions. $J$ Water Health. 2017;15(4):555-565. doi:10.2166/wh.2017.052

68. Manivasagan P, Venkatesan J, Senthilkumar K, Sivakumar K, Kim S$\mathrm{K}$. Biosynthesis, antimicrobial and cytotoxic effect of silver nanoparticles using a novel nocardiopsis sp. MBRC-1. Biomed Res Int. 2013;2013:1-9. doi:10.1155/2013/287638

69. Youssif KA, Haggag EG, Elshamy AM, et al. Anti-Alzheimer potential, metabolomic profiling and molecular docking of green synthesized silver nanoparticles of Lampranthus coccineus and Malephora lutea aqueous extracts. PLoS One. 2019;14:11. doi:10.1371/journal.pone.0223781

70. Cheng SY, Wen ZH, Wang SK, et al. Revision of the absolute configuration at $\mathrm{C}$ (23) of lanostanoids and isolation of secondary metabolites from Formosan soft coral Nephthea erecta. Chem Biodivers. 2009;6(1):86-95. doi:10.1002/cbdv.200800015

71. Izac RR, Bandurraga MM, Wasylyk JM, Dunn FW, Fenical W. Germacreme derivatives from diverse marine soft-corals (octocorallia). Tetrahedron. 1982;38(2):301-304. doi:10.1016/0040-4020(82)80011-2

72. Rao CB, Sekhar VC, Sarvani B, Rao DV. A new oxygenated tricyclic sesquiterpene from a soft coral of Nephthea species of Andaman and Nicobar coasts of Indian ocean. ChemInform. 2004;35. doi:10.1002/ chin. 200442198

73. Ahond A, Chiaroni A, Coll J, et al. Studies of Australian Soft Corals. XVII. The isolation and properties of Lemnalactone, 7-EPILemnalactone and their derivatives. A correction of several literature assignments, supported by X-Ray diffraction. Bulletin des Sociétés chimiques belges. 1979;88(5):313-324. doi:10.1002/bscb.19790880507

74. Jurek J, Scheuer PJ. Sesquiterpenoids and norsesquiterpenoids from the soft coral Lemnalia africana. J Nat Prod. 1993;56(4):508-513. doi:10.1021/np50094a009

75. Bowden BF, Coll JC, Engelhardt LM, Tapiolas DM, White AH. Studies of Australian Soft Corals. XXXVI. The isolation and structure determination of 11 Calamenene-based sesquiterpenes from Lemnalia-Cervicornis (Coelenterata, Octocorallia, Alcyonacea). Aust J Chem. 1986;39(1):103-121. doi:10.1071/CH9860103

76. Coll J, Mitchell S, Stokie G. Studies of Australian soft corals. V-A novel furano-sesquiterpene acid from the soft coral sinularia gonatodes (Kolonko). Tetrahedron Lett. 1977;18(18):1539-1542. doi:10.1016/S0040-4039(01)93097-7

77. Rahelivao MP, Lübken T, Gruner M, et al. Isolation and structure elucidation of natural products of three soft corals and a sponge from the coast of Madagascar. Org Biomol Chem. 2017;15(12):2593-2608. doi:10.1039/C7OB00191F

78. Su JH, Hsieh CH, Lo CL, et al. Sesquiterpenoids-related Metabolites from the Soft Coral Sinularia sp. J Chinese Chem Soc. 2008;55 (6): 1286-1289. doi:10.1002/jccs.200800192

79. Williams D, Andersen RJ, Van Duyne GD, Clardy J. Cembrane and pseudopterane diterpenes from the soft coral Gersemia rubiformis. $J$ Org Chem. 1987;52(3):332-335. doi:10.1021/jo00379a002

80. Blunt JW, Carroll AR, Copp BR, Davis RA, Keyzers RA, Prinsep MR. Marine natural products. Nat Prod Rep. 2018;35(1):8-53.

81. Cheng S-Y, Huang Y-C, Wen Z-H, et al. New 19-oxygenated and 4methylated steroids from the Formosan soft coral Nephthea chabroli. Steroids. 2009;74(6):543-547. doi:10.1016/j.steroids.2009.02.004
International Journal of Nanomedicine

\section{Publish your work in this journal}

The International Journal of Nanomedicine is an international, peerreviewed journal focusing on the application of nanotechnology in diagnostics, therapeutics, and drug delivery systems throughout the biomedical field. This journal is indexed on PubMed Central, MedLine, CAS, SciSearch ${ }^{\mathbb{R}}$, Current Contents ${ }^{\mathbb{R}} /$ Clinical Medicine, $^{2}$
Journal Citation Reports/Science Edition, EMBase, Scopus and the Elsevier Bibliographic databases. The manuscript management system is completely online and includes a very quick and fair peer-review system, which is all easy to use. Visit http://www.dovepress.com/ testimonials.php to read real quotes from published authors. 